\title{
Recent advances in luminescent metal-organic frameworks for chemical sensors
}

\author{
Jie $\mathrm{He}^{1}$, Jialiang $\mathrm{Xu}^{1}$, Jiacheng $\mathrm{Yin}^{1},{\mathrm{Na} \mathrm{Li}^{1 *}}^{{ }^{*}}$ and Xian- $\mathrm{He} \mathrm{Bu}^{1,2^{*}}$
}

\begin{abstract}
Metal-organic frameworks (MOFs), comprised of metal ions/clusters and organic ligands, have shown promising potential for numerous applications. Recently, luminescent MOFs (LMOFs), with the superiorities of inherent crystallinity, definite structure, tunable pore, and multiple functionalizations, have bloomed out as sensors for the detection. Numerous LMOFs have been synthesized and used for sensing applications. Herein, the recent advances of LMOFs as chemical sensors for the detection of diverse targets, including metal ions, anions, small molecules, volatile organic compounds, nitro-aromatic explosives, gases, and biomolecules, have been summarized. Additionally, the detection mechanisms and the relationship between structure and properties of the materials are also illustrated. This review could be useful reference for the rational construction and sensing applications of LMOFs.
\end{abstract}

Keywords: metal-organic frameworks, chemical sensors, luminescence, detection mechanisms

\section{INTRODUCTION}

As one of the most promising classes of porous materials, metal-organic frameworks (MOFs), constructed from organic ligands and metal ions or clusters via coordination bonds, have gained intensive attention for their highly regulable pore geometry and ultra-high porosity [1], which leads to their widespread applications in molecular separation [2-5], catalysis [6-10], gas storage [11$15]$, drug delivery [16,17], and sensing [18-22]. Recently, luminescent MOFs (LMOFs) have bloomed out as an interesting family of porous materials for sensing applications $[23,24]$. Compared with the organic luminescent polymers, LMOFs are more attractive as chemical sensors owing to their key advantages in structural characteristics, functional components, and interactions between MOFs and analytes.

The precise structure of MOFs from their inherent crystallinity is beneficial for sufficiently understanding the LMOFs-analyte sensing interactions in the detection process. More importantly, the rational choice of the organic and metal components offers diverse compositions and porosities. This, in turn, enables facile regulation of LMOFs-analyte interactions to promote the recognition capability of targets. For example, the incorporation of the fluorescent ligands with aromatic moieties or conjugated $\pi$-systems and metal resources with fluorescence emission into MOFs to fabricate LMOFs can dramatically vary the luminescent properties of LMOFs and therefore promise different sensing applications. Furthermore, the intrinsic porosity of LMOFs also provides multiple advantages. This porosity offers a suitable architecture to accommodate the analytes, which can facilitate the capture of analytes and improve the sensing performance. In addition, the tunable porosities endow LMOFs with suitable host structures for adsorbing and releasing guest molecules, thereby resulting in enhanced sensing performance towards specific targets [13,25-27]. For example, the pore structures of MOFs can be effectively tuned by introducing various functional groups, such as $-\mathrm{NH}_{2},-\mathrm{HSO}_{3},-\mathrm{CONH}_{2}$, binaphthol, and pyridyl, to improve the detection performance for analytes $[28,29]$. It should be noted that the pore characteristics of LMOFs (including size, shape, pore environment, etc.) can be designed and regulated for controlling the sensing interactions, which could often benefit the sensing performance.

\footnotetext{
${ }^{1}$ School of Materials Science and Engineering, National Institute for Advanced Materials, Tianjin Key Laboratory of Metal and Molecule-Based Material Chemistry, Nankai University, Tianjin 300350, China

${ }^{2}$ State Key Laboratory of Elemento-Organic Chemistry, College of Chemistry, Nankai University, Tianjin 300071, China

* Corresponding authors (emails: buxh@nankai.edu.cn (Bu XH); lina@nankai.edu.cn (Li N))
} 
Many efforts have been dedicated to the design and synthesis of new LMOFs materials for sensing applications, which triggers the blooming research of LMOFs. Numerous LMOFs with diverse structures and sensing applications have been reported due to the tunability and functionalization of LMOFs that could immensely influence the resultant luminescent properties. Subsequently, new mechanisms involving the charge-transfer and energy-transfer processes [24,30,31], such as ligand-tometal charge transfer (LMCT), metal-to-ligand charge transfer (MLCT), ligand-to-ligand charge transfer (LLCT), metal-to-metal charge transfer (MMCT), have been proposed [32,33]. Some methods have been developed to construct LMOFs for luminescent sensors by means of pore functionalization, topology design, luminescent centers inserting and so on. It should be noted that various features of LMOFs make the modulation towards sensing performance relatively more complicated. Hence, analyzing and summarizing the relationship between structures and properties of the materials is of great significance for the rational construction and modulation of new LMOFs system.

Herein, we highlight the recent advances of LMOFs in terms of sensing applications for different targets, including ions, nitro-aromatic explosives, volatile organic compounds (VOCs), small molecules, gases, and biomolecules (Scheme 1). We illustrate the key role of LMOFs as luminescent sensors in structure tuning and function realization, which could be instructively useful for related research investigations.

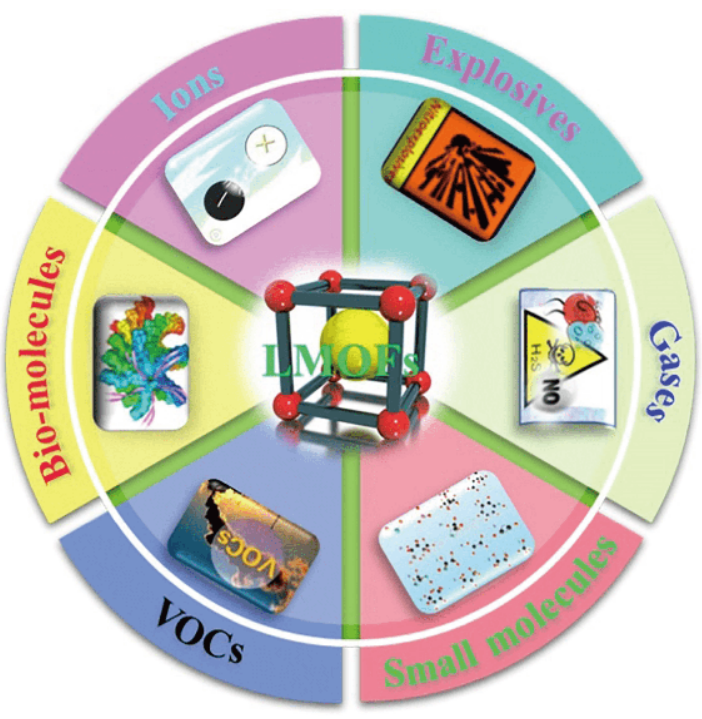

Scheme 1 Luminescent metal-organic frameworks for a variety of sensing applications.

\section{LMOFs FOR SENSING}

\section{Sensing of ions}

The detection and identification of ions have irreplaceable significance in life, health, environmental protection, and nuclear industry. For some metal ions, highly efficient detection and identification as well as recovery are of great significance in industry. It is also critical to quickly detect and identify some other non-metal ions with high sensitivity. MOFs have been applied for detecting a variety of metal cations and anions [34]. By taking advantages of their inorganic-organic component, the structures and properties of LMOFs can be systematically and regularly adjusted to gain tunable fluorescence sensing performance. In this section, some representative examples for the detection of ions are reviewed.

\section{Metal cations}

Iron ions play an essential role in the body as well as many living organisms [35]. However, excess or deficiency of iron often causes various physiological disorders and even induces cancers [36]. LMOFs can be promising fluorescence sensors to selectively detect $\mathrm{Fe}^{3+}$ [37-41]. Bu and co-workers [39] constructed a new porous lanthanide MOF $\left[\operatorname{EuL} 1(\mathrm{OH})_{2}\right]\left(\mathrm{NO}_{3}\right) \cdot x$ (solvent) $\left(1, \mathrm{~L} 1=1,1,1^{\prime}, 1^{\prime \prime}\right.$ (2,4,6-trimethylbenzne-1,3,5-triyl)-tris(methylene)-tris(4carboxypyridinium)tribromide), based on a tripodal flexible zwitterion ligand. The compound $\mathbf{1}$ exhibited high sensitivity and selectivity for the detection of $\mathrm{Fe}^{3+}$ through a luminescence "turn-off" response. $\mathrm{Fe}^{3+}$ completely quenched the emission of MOF as observed by naked-eyes under UV light when 1 was immersed in $N$, $N^{\prime}$-dimethylacetamide (DMAC) solutions containing different metal cations. Markedly, this detection was driven by the competition absorption and the electronic interactions between $\mathrm{Fe}^{3+}$ and the L1 ligands. Later, Bu et al. [40] fabricated a porous three dimensional (3D) LMOF, $[\mathrm{ZnL} 2] \cdot x \mathrm{G}\left(2, \mathrm{G}=\right.$ guest molecules, $\mathrm{H}_{3} \mathrm{~L} 2 \mathrm{Cl}=N$ (3,5-dicarboylphenyl)- $N^{\prime}$-(4-carboxylbenzyl)imidazolium chloride), which exhibited a "turn-off" sensing activity for $\mathrm{Fe}^{3+}$ ions with excellent selectivity attributed to the energy transfer from $\mathrm{L}^{2-}$ to metal ions. It should be noted that compound $\mathbf{2}$ displayed excellent regeneration ability without losing its crystalline and luminescent intensity after twenty cycles. Later, Sun and co-workers [41] constructed three Cd-based MOFs, $\left[\mathrm{Cd}_{2} \mathrm{Na}(\mathrm{L} 3)(\mathrm{BDC})_{2.5}\right]$. $9 \mathrm{H}_{2} \mathrm{O}(3, \quad \mathrm{BDC}=$ terephthalic acid $), \quad\left[\mathrm{Cd}_{2}(\mathrm{~L} 3)(2,6-\right.$ $\left.\mathrm{NDC})_{2}\right] \cdot \mathrm{DMF} \cdot 5 \mathrm{H}_{2} \mathrm{O}(4,2,6-\mathrm{NDC}=2,6$-naphthalenedicarboxylic acid, DMF $=N, N^{\prime}$-dimethyl formamide), and 
$\left[\mathrm{Cd}_{2}(\mathrm{~L} 3)(\mathrm{BPDC})_{2}\right] \cdot$ DMF. $9 \mathrm{H}_{2} \mathrm{O}$ (5, BPDC $=4,4^{\prime}$-diphenyldicarboxylic acid), where L3 represents $N^{\prime}-(4-(1 H-$ 1,2,4-triazole-1-yl)benzyl)- $N^{\prime}$-(2-amino-ethyl)ethane-1,2diamine. These MOFs can be used as effective sensors to identify $\mathrm{Fe}^{3+}$ with a quenching fluorescence response due to competition absorption of excitation energy between $\mathrm{Fe}^{3+}$ and the three LMOFs.

Besides iron ions, the sensing of other metal ions, such as $\mathrm{Cu}^{2+}, \mathrm{Ba}^{2+}, \mathrm{Al}^{3+}, \mathrm{Ce}^{2+}$, has been also reported with MOF-based chemical sensors [42-47]. For example, an anionic microporous MOF with unsaturated coordination sites, $\quad\left[\mathrm{NH}_{2}\left(\mathrm{CH}_{3}\right)_{2}\right]\left(\mathrm{H}_{2} \mathrm{O}\right) \cdot\left[\mathrm{Zn}_{3}(\mathrm{BTA})(\mathrm{BTC})_{2}\right]$. 4DMAC $3 \mathrm{H}_{2} \mathrm{O}(6, \mathrm{BTA}=$ benzotriazolate, $\mathrm{BTC}=1,3,5$ benzenetricarboxylic acid), has been rationally designed and constructed by $\mathrm{Bu}$ and co-workers [42] to detect $\mathrm{Ba}^{2+}$ and $\mathrm{Cu}^{2+}$ ions. The luminescent intensity of $\mathbf{6}$ was quenched by about $45 \%$ when incorporated with $\mathrm{Cu}^{2+}$ in DMAC solutions due to the exchange of $\left[\mathrm{NH}_{2}\left(\mathrm{CH}_{3}\right)_{2}\right]^{+}$ with $\mathrm{Cu}^{2+}$ ions. Inversely, the fluorescence intensity of $\mathrm{Ba}^{2+}$-incorporated 6 was enhanced by about $23 \%$. Yang et al. [43] used the mixed ligand strategy to construct a 3D MOF $\left[\mathrm{Cd}_{2}(\mathrm{DTP})_{2}(\mathrm{bibp})_{1.5}\right]_{n}\left(7, \mathrm{H}_{2} \mathrm{DPT}=4^{\prime}\right.$-(4-(3,5-dicarboxylphenoxy)phenyl)-4,2':6',4"-terpyridine, bibp = 1,3-di(1H-imidazol-1-yl)propane). It was demonstrated that $\mathrm{Cu}^{2+}$ can be efficiently and selectively detected by 7 in DMF.

The majority of MOFs used to detect $\mathrm{Al}^{3+}$ ions are derived from the fluorescence quenching. Examples of fluorescence-intensity enhancement, that is, a "turn-on" behavior for $\mathrm{Al}^{3+}$ ions sensing, are scarce [44]. Recently, $\mathrm{Bu}$ and co-workers [45] realized the "turn-on" detection of $\mathrm{Al}^{3+}$ ions utilizing a new 3D MOF, $\left\{\mathrm{Zn}_{2}(\mathrm{O}-\mathrm{BTC})\left(4,4^{\prime}-\right.\right.$ BPY $\left.)_{0.5}\left(\mathrm{H}_{2} \mathrm{O}\right)_{1.5} \cdot(\mathrm{DMA})_{0.5}\right\}_{n}(\mathbf{8})$. It is based on 2-hydroxybenzene-1,3,5-tricarboxylic acid $\left(\mathrm{HO}-\mathrm{H}_{3} \mathrm{BTC}\right)$ and 4,4'bipyridine $\left(4,4^{\prime}\right.$-BPY) ligands in which the pyridine rings from $4,4^{\prime}$ - $\mathrm{BPY}$ are parallelly arranged in the pores of the framework. Although the fluorescence emission of compound $\mathbf{8}$ itself is low, it is an excellent fluorescence sensor with a low detection limit of $0.10 \mathrm{ppm}$ for $\mathrm{Al}^{3+}$ (Fig. 1a). The emission intensity was increased sharply when $\mathbf{8}$ was used to detect $\mathrm{Al}^{3+}$ ions in the $\mathrm{C}_{2} \mathrm{H}_{5} \mathrm{OH}$ solution. The luminescence intensity of $\mathbf{8}$ was significantly increased by about 7 times in $\mathrm{Al}^{3+}$ ions solution. This prompted the realization of the high-selectivity $\mathrm{Al}^{3+}$ sensing (Fig. 1b). Particularly, it was found that $4,4^{\prime}$-BPY played an important role in the detection process as a "guest molecule" to facilitate the electronic transfer [46].

The pore structure of MOFs is a critical factor to promote the sensing performance. Sun and co-workers [47] reported a 3D porous MOF decorated with exposed

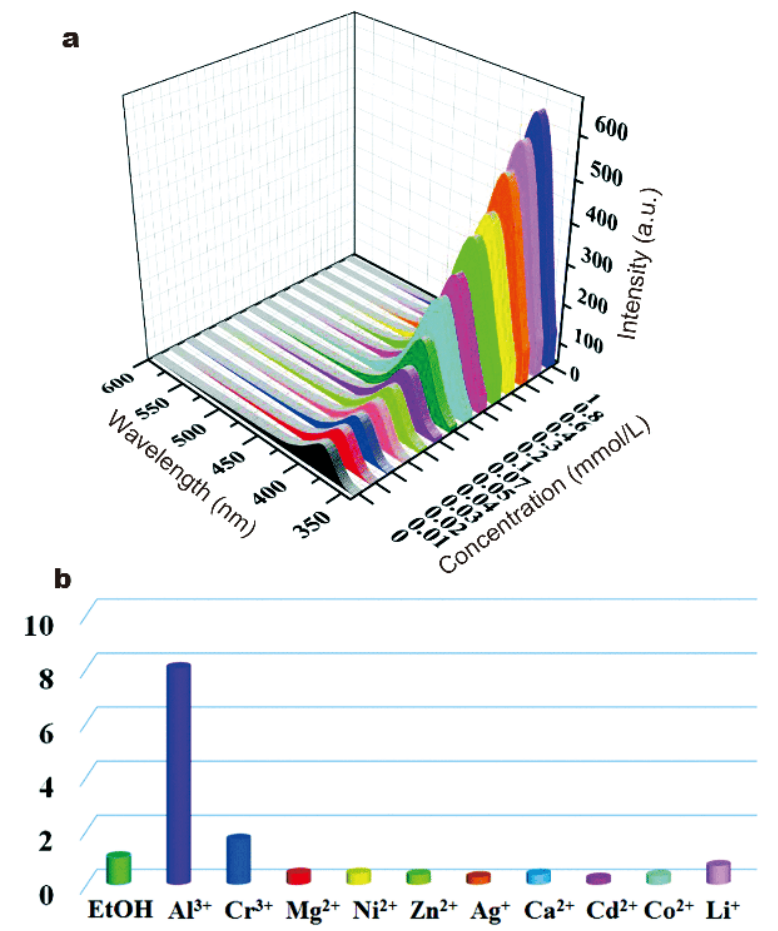

Figure 1 (a) Luminescence spectra of 8 upon the addition of different metal ions in the $\mathrm{C}_{2} \mathrm{H}_{5} \mathrm{OH}$ solution $\left(1 \times 10^{-3} \mathrm{~mol} \mathrm{~L}^{-1}\right)$. (b) Liquid luminescence spectra of 8 in different $\mathrm{Al}^{3+}$ concentrations from $1.0 \times 10^{-5}$ to $1 \times 10^{-3} \mathrm{~mol} \mathrm{~L}^{-1}$. Room temperature, $\lambda_{\mathrm{ex}}=324 \mathrm{~nm}$. Reprinted with permission from Ref. [45]. Copyright 2016, Royal Society of Chemistry.

pyrimidyl Lewis base sites, $\left[\mathrm{Co}_{2}(\mathrm{dmimpym})(\mathrm{nda})_{2}\right]_{n}(\mathbf{9}$, dmimpym $=4,6$-di (2-methylimidazol-1-yl)-pyrimidine, $\mathrm{H}_{2}$ nda $=1$,4-naphthalenedicarboxylic acid), in which pyrimidyl $\mathrm{N}$ atom in the paralleling pyridine rings and $\mathrm{Al}^{3+}$ ions can be used to bond with analytes. With the increasing amount of $\mathrm{Al}^{3+}$, the luminescent intensity was significantly enhanced and the absolute quantum yield of the original framework increased from $1.5 \%$ to $2.9 \%$, attributed to the bonding interactions between $\mathrm{Al}^{3+}$ and pyrimidyl $\mathrm{N}$ of the ligand which increased the electron transition process. Li et al. [48] constructed an excitedstate intramolecular proton transfer (ESIPT)-based LMOF, namely Mg-TPP-DHBDC (TPP $=6$ ' -(pyridin- 4 yl)-4,2':4',4"-terpyridine, DHBDC = 2,5-dihydroxybenzene-1,4-dicarboxylic acid). The intramolecular hydrogen bonds between $-\mathrm{OH}$ and $-\mathrm{COOH}$ of DHBDC ligand induce the ESIPT process. With the increase of the concentration of $\mathrm{Al}^{3+}$ ions, this process was disturbed, the "first turn-off and then turn-on" response was observed. As a result, the sensor exhibited high sensitivity and selectivity towards $\mathrm{Al}^{3+}$ in the range of $0-15 \mu \mathrm{m}$. The unusual response was due to the strong coordination 
bonds between the -OH from DHBDC ligand and $\mathrm{Al}^{3+}$. Meanwhile, the highly desirable naked eyes detection towards trace level of $\mathrm{Al}^{3+}$ ions can also be realized by Mg-TPP-DHBDC.

The chemical stability of MOFs plays an important role with regard to their wide range of application fields. To date, a number of MOFs featuring high-level chemical stability have been developed for the detection of metal ions. Zhang et al. [49] reported a new Ln-MOF $\left[\mathrm{Tb}_{4^{-}}\right.$ $\left.\left(\mu_{6}-\mathrm{L} 4\right)_{2}(\mu-\mathrm{HCOO})\left(\mu_{3}-\mathrm{OH}\right)_{3}\left(\mu_{3}-\mathrm{O}\right)(\mathrm{DMF})_{2}\left(\mathrm{H}_{2} \mathrm{O}\right)_{4}\right]_{n} \quad(\mathbf{1 0})$ composed of $\mathrm{Tb}^{3+}$ secondary building units (SBUs) and [2-(5-carboxypyridin-3-yl)terephthalic acid] $\left(\mathrm{H}_{3} \mathrm{~L} 4\right)$ ligands. Compound 10 exhibited a high sensitivity and low detection limit towards $\mathrm{Ce}^{2+}$. Remarkably, the weak interactions between pyridine nitrogen atoms of the ligand within 10 and the analyte enhanced the fluorescent quenching and improved the sensitivity.

$\mathrm{Hg}$ (II) ions, highly toxic to both environmental and human beings, have attracted increasing attention, and many researchers have investigated the utilization of LMOFs for probing $\mathrm{Hg}^{2+}$. On the basis of the tunable hostguest interactions between LMOFs and analytes, most of the MOFs containing nitrogen centers, amine groups, and alkyne groups, have also been designed and investigated for probing $\mathrm{Hg}^{2+}$ [50,51]. Recently, Ghosh and co-workers [50] prepared a butyne-functionalized UiO-66 luminescent MOF (UiO-66@butyne) that can detect $\mathrm{Hg}^{2+}$ in aqueous solution with a high chemical and hydrolytic stability (Fig. 2a and b). Meanwhile, this MOF exhibited a high selectivity towards $\mathrm{Hg}^{2+}$ with an extremely low limit of detection (LOD) of $10.9 \mathrm{nmol} \mathrm{L}^{-1}$ (Fig. 2c) and a fast response time of just $3 \mathrm{~min}$ (Fig. 2d). It was found that the butyne groups can obviously quench the fluorescence of UiO-66@butyne through the oxymercuration reaction. Similarly, a functional MOF $\left\{\left[\mathrm{Zn}\left(4,4^{\prime}-\mathrm{AP}\right)(5-\mathrm{AIA})\right]-\right.$ $\left.(\mathrm{DMF})_{0.5}\right\}_{n}$ with nitrogen-containing ligands, $\left[4,4^{\prime}-\mathrm{AP}=\right.$ 4,4-azopyridine, 5-AIA $=5$-aminoisophthalic acid], has also been prepared to detect $\mathrm{Hg}^{2+}$ with a low LOD by Mandal and co-workers [51]. In this system, the bonding interactions between $\mathrm{Hg}(\mathrm{II})$ and $-\mathrm{N}=\mathrm{N}$ - group of $4,4^{\prime}-\mathrm{AP}$ contributed to the electron delocalization of the framework and to quench the fluorescence.

\section{Anions}

Hexavalent chromium $\left(\mathrm{Cr}^{\mathrm{VI}}\right)$ is one of the most toxic heavy metal pollutants [52,53]. Recently, some LMOFs stemming from the appropriate choice of organic and inorganic components have been reported to be ex-
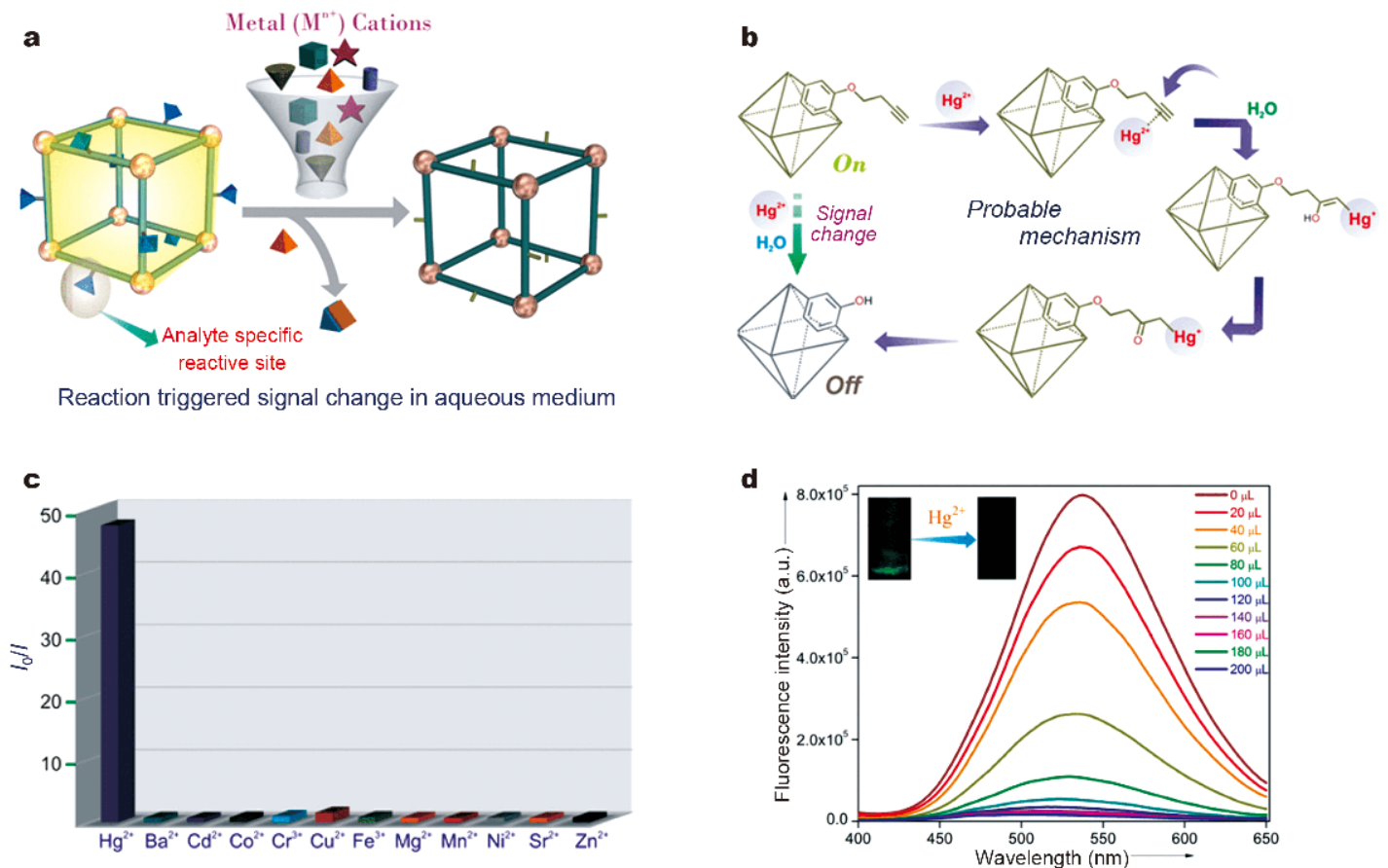

Figure 2 (a) Detection of $\mathrm{Hg}$ (II) in a water medium with a functionalized MOF. (b) Schematic representation of the probable mechanism of Hg(II) sensing in UiO-66@butyne. (c) The extent of the fluorescence response of UiO-66@butyne toward various metal ions. (d) Emission spectra of UiO66@butyne at $537 \mathrm{~nm}$ dispersed in water medium on incremental addition of $\mathrm{Hg}(\mathrm{II})$ solution. Reprinted with permission from Ref. [50]. Copyright 2018, American Chemical Society. 
peditious for the detection of chromium-containing anions. For example, Yao et al. [54] selected the luminescent ligands to fabricate a water-stabilized Zn-based LMOF featuring triangular channels, namely $\left\{\left[\mathrm{Zn}_{3}\right.\right.$ (bpanth)$\left.\left.(\text { oba })_{3}\right] \cdot 2 \mathrm{DMF}\right\}_{n}(11$, bpanth $=9,10$-bis $(4$-pyridyl)anthracene, $\mathrm{H}_{2} \mathrm{Oba}=4,4^{\prime}$-oxybis(benzoic acid). Compound $\mathbf{1 1}$ displayed a fast and selective fluorescent quenching response towards $\mathrm{Cr}_{2} \mathrm{O}_{7}{ }^{2-} / \mathrm{CrO}_{4}{ }^{2-}$ with a low LOD (0.7 and $0.3 \mathrm{ppm}$ for $\mathrm{Cr}_{2} \mathrm{O}_{7}{ }^{2-}$ and $\mathrm{CrO}_{4}{ }^{2-}$, respectively) because of the competitive absorption and resonance energy transfer between the $\mathbf{1 1}$ and $\mathrm{Cr}^{\mathrm{VI}}$ ions (Fig. 3). Notably, 11 can be easily and quickly regenerated. The strong interactions between metal clusters and analytes of anions have been shown to induce the high sensing capacity of MOFs. He et al. [55] reported a $\mathrm{Zr}(\mathrm{IV})-\mathrm{MOF}$ by using a T-shaped ligand $\mathrm{H}_{3} \mathrm{BTBA}, \mathrm{Zr}_{6} \mathrm{O}_{4}(\mathrm{OH})_{7}\left(\mathrm{H}_{2} \mathrm{O}\right)_{3}(\mathrm{BTBA})_{3}(\mathbf{1 2})(\mathrm{BTBA}=$ $4,4^{\prime}, 4^{\prime \prime}$-( $1 \mathrm{H}$-benzo[d]imidazole-2,4,7-triyl)tribenzoic acid). 12 can serve as a highly selective and sensitive "turn-off" fluorescent probe for the detection of $\mathrm{Cr}^{\mathrm{VI}}$ governed by the competition absorption and the hostguest interactions derived from the coordination interactions between the $\mathrm{Zr}_{6}$ node of MOF and $\mathrm{Cr}_{2} \mathrm{O}_{7}{ }^{2-}$ anions. The cationic LMOFs can be also considered as ideal chemical sensors to detect the anions arising from the particular anion exchange capacities.

A series of MOF-based sensors as a platform for efficiently detecting anions by means of anion exchange, such as $\mathrm{F}^{-}, \mathrm{Cl}^{-}, \mathrm{Br}^{-}, \mathrm{I}^{-}, \mathrm{N}_{3}^{-}, \mathrm{CN}^{-}$and $\mathrm{SCN}^{-}$, have been reported [56]. In these systems, the free counterions in the channel can be facilely replaced by target anions to vary the sensing properties [57-60]. Bu and co-workers [57] used a neutral organic ligand and $\mathrm{Cu}$ salts to construct a cationic 4-fold interpenetration framework $\{[\mathrm{Cu}$ (pytpy)] $\left.\cdot \mathrm{NO}_{3} \cdot \mathrm{H}_{2} \mathrm{O}\right\}_{\infty}(13$, pytpy $=2,4,6$-tris(4-pyridyl)pyridine) (Fig. 4a). 13 can efficiently detect the different

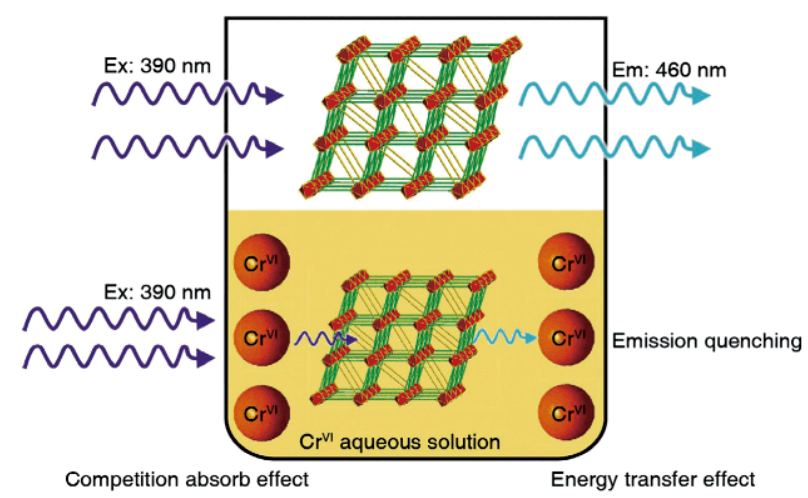

Figure 3 The possible quenching mechanism for detecting $\mathrm{Cr}^{\mathrm{VI}}$ by $\mathbf{1 1}$. Reprinted with permission from Ref. [54]. Copyright 2018, Wiley-VCH. anions including $\mathrm{F}^{-}, \mathrm{Cl}^{-}, \mathrm{Br}^{-}, \mathrm{I}^{-}, \mathrm{N}_{3}^{-}, \mathrm{CN}^{-}, \mathrm{SCN}^{-}$, and $\mathrm{CO}_{3}{ }^{2-}$ in aqueous solutions by a "turn-off" mechanism accompanied by the replacement of the partial nitrate with different anions in its channels. More importantly, the ion-exchange process of $\mathbf{1 3}$ can be conveniently identified by naked-eyes (Fig. 4b). Another cationic fluorescence $\mathrm{Cu}^{\text {II }}$-based MOF showing visual inspection detection in response to the above mentioned anions through an anion-exchange process was reported by Dong's group [58]. Later, Manna et al. [59] have also successfully synthesized a cationic framework Zn-MOF, $\left.\left\{\mathrm{Zn}(\mathrm{L} 5)\left(\mathrm{OH}_{2}\right)_{2}\right\}\left(\mathrm{NO}_{3}\right)_{2} \cdot x \mathrm{G}\right]_{n}(\mathbf{1 4}$, L5 = 4,4'-(ethane-1,2diyl)bis( $N$-(pyridin-2-yl-methylene)aniline). It was capable of selectively detecting some non-coordinated or weakly coordinated anions such as $\mathrm{ClO}_{4}^{-}, \mathrm{PF}_{6}^{-}$, and $\mathrm{BF}_{4}^{-}$ in aqueous solution via ion exchange. Interestingly, this

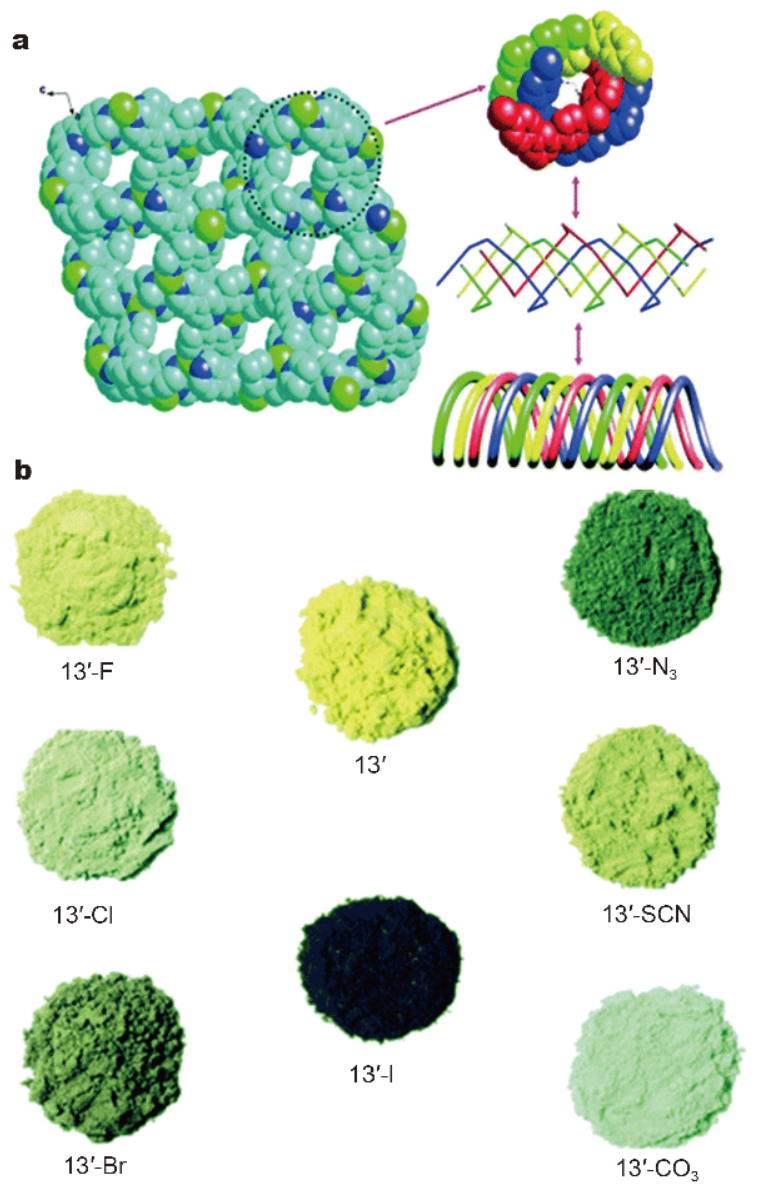

Figure 4 (a) A space-filling diagram of the 4-fold interpenetration in $\mathbf{1 3}$ viewed along the crystallographic $b$-axis (solvent molecules and nitrate anions omitted) (left); views of the single 4 -fold helical channel (right). (b) The color of activated $\mathbf{1 3}$ and different anion-exchanged complexes. Reprinted with permission from Ref. [57]. Copyright 2013, Royal Society of Chemistry. 
framework exhibited anion-dependent tunable luminescence and sorption behaviors.

It is well known that the $\mathrm{I}^{-}$from industrial processes and nuclear waste is one of the most hazardous contaminants, and can induce serious health problems. Recently, Shi et al. [60] constructed two cationic heterometal-organic frameworks with formulas of $\left[\mathrm{Ln}_{2} \mathrm{Zn}\right.$ $\left.(\mathrm{L} 6)_{3}\left(\mathrm{H}_{2} \mathrm{O}\right)_{4}\right] \cdot\left(\mathrm{NO}_{3}\right)_{2} \cdot 12 \mathrm{H}_{2} \mathrm{O}(\mathrm{Ln}=\mathrm{Eu}, 15 ; \mathrm{Ln}=\mathrm{Tb}, 16$; $\mathrm{L} 6$ $=4,4^{\prime}$-dicarboylate-2,2'-dipyridine anion) (Fig. 5a). These heterometal-organic frameworks are highly sensitive and efficient luminescent probes for $\mathrm{I}^{-}$in aqueous solution with a fast response time of $10 \mathrm{~s}$ and a very low LOD of $0.001 \mathrm{ppm}$ in the presence of back ground anions including $\mathrm{F}^{-}, \mathrm{Cl}^{-}, \mathrm{H}_{3} \mathrm{COO}^{-}, \mathrm{NO}_{3}^{-}, \mathrm{H}_{2} \mathrm{PO}_{4}^{-}, \mathrm{HSO}_{3}^{-}, \mathrm{HCO}_{3}^{-}$, $\mathrm{CO}_{3}{ }^{2-}, \mathrm{SO}_{4}{ }^{2-}, \mathrm{SO}_{3}{ }^{2-}$, and $\mathrm{PO}_{4}{ }^{3-}$ (Fig. 5b). Particularly, it was demonstrated that $\mathrm{I}^{-}$embedded in the channels through ion exchange can be oxidized to obtain $\mathrm{I}_{3}{ }^{-}$with the help of the cationic framework, resulting in luminescence quenching. In this way, the resulting MOF sensor exhibited single $\mathrm{I}^{-}$detection compared with other anions in a fluorescence "turn off" process and could be recycled for up to ten times by immersing the MOFs in a
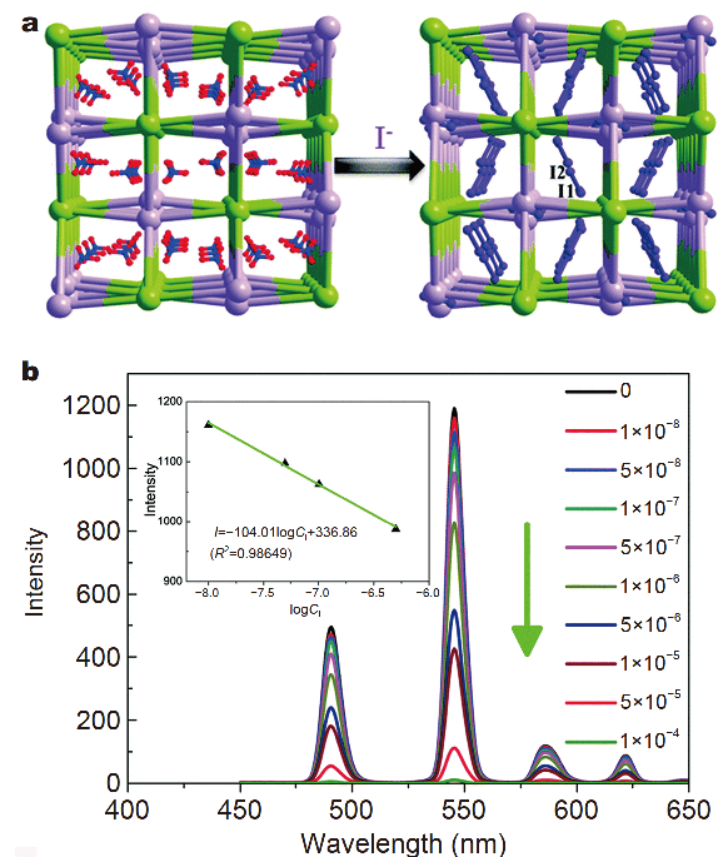

Figure 5 (a) 3D framework of $\mathbf{1 5}$ or $\mathbf{1 6}$ and the position of $\mathrm{NO}_{3}{ }^{-}$in the channels (left); I-I bonds in the channels (C, gray; $\mathrm{N}$, blue; $\mathrm{O}$, red; $\mathrm{H}$ atoms and free water molecules are omitted for clarity) (right). (b) The liquid fluorescence spectra of $\mathbf{1 5}$ under different concentrations of KI aqueous solution $\left(\mathrm{mol} \mathrm{L}^{-1}\right.$ ) upon excitation at $343 \mathrm{~nm}$ and the corresponding plots of intensity $v s . \log C_{\mathrm{I}}$ in the concentration range of $1 \times 10^{-8}$ $-1 \times 10^{-6} \mathrm{~mol} \mathrm{~L}^{-1}$ (inset). Reprinted with permission from Ref. [60]. Copyright 2013, Royal Society of Chemistry. saturated $\mathrm{KNO}_{3}$ solution.

Besides the intrinsic structural character, a portion of weak interactions between the frameworks and sensing targets also contribute to the variation of luminescence intensity, which usually occurs in MOFs containing $\mathrm{N}-\mathrm{H}$ and $\mathrm{O}-\mathrm{H}$ moieties and terminal coordinated organic solvent $[61,62]$. For example, the hydrogen bonding between the anions and $\mathrm{OH}$ groups of the ligands can enhance the luminescent intensity of MOF [Tb(Mucicate) $\left.)_{1.5} \cdot 3\left(\mathrm{H}_{2} \mathrm{O}\right)_{2}\right] \cdot 5 \mathrm{H}_{2} \mathrm{O}$ [61]. Chen et al. [62] successfully constructed a porous LMOF $\left\{\mathrm{Tb}(\mathrm{BTC}) \cdot\left(\mathrm{CH}_{3}-\right.\right.$ $\mathrm{OH})\}$ (MOF-76) containing coordinate ethanol solvent in its $1 \mathrm{D}$ channels. The addition of $\mathrm{F}^{-}$enhanced the emission intensity of MOF-76 much more significantly than other anions such as $\mathrm{Br}^{-}, \mathrm{Cl}^{-}, \mathrm{SO}_{4}{ }^{2-}$, and $\mathrm{CO}_{3}{ }^{2-}$, due to the formation of strong hydrogen bond between $\mathrm{F}^{-}$and the $\mathrm{O}-\mathrm{H}$ group of terminal methanol molecules.

Compared with the above-mentioned single-response MOF sensors, ratiometric sensors based on MOFs with multiple emission bands are more attractive for sensing applications for their advantages of self-calibration. The self-calibrating mechanisms can minimize the numerous environmental influence factors, thereby improving the sensing accuracy, sensitivity and selectivity [63,64]. A ratiometric fluorescence Eu-MOF (17) comprised of 5boronoisophthalic acid (5-bop) and $\mathrm{Eu}^{3+}$ was reported by Yang et al. [63]. The introduction of boric acid could tune the energy level of the ligand, thus endowing 17 with two emissive centers at the single excitation of $275 \mathrm{~nm}$. This originated from the combination of $\mathrm{T}_{1}$ energy level of the boric acid functionalized ligands and the energy gap between $\mathrm{T}_{1}$ and $\mathrm{Eu}^{3+}$ ions. The dual-fluorescence emission Eu-MOF can be used as sensors to identify aqueous fluoride ions with a low LOD of $2 \mu \mathrm{mol} \mathrm{L}^{-1}$. As the fluoride concentration increased, the luminescent intensity of the 5-bop center of $\mathbf{1 7}$ increased, but that of $\mathrm{Eu}^{3+}$ decreased, along with color changed from red to blue (Fig. $6 \mathrm{a}$ and $\mathrm{b}$ ). The color and intensity change could be observed by naked eyes. Meanwhile, the interactions between $\mathrm{F}^{-}$and the boron of ligand contributed to the change of the fluorescence properties.

MOFs as chemical sensors can also be extended to recognize other anions such as $\mathrm{CO}_{3}{ }^{2-}, \mathrm{SO}_{4}{ }^{2-}, \mathrm{SO}_{3}{ }^{2-}$, $\mathrm{MnO}_{4}{ }^{2-}, \mathrm{ClO}^{-}, \mathrm{C}_{2} \mathrm{O}_{4}{ }^{2-}$, and $\mathrm{PO}_{3}{ }^{4-}$. Ji et al. [64] reported a $\mathrm{Tb}^{3+}$ doped dual-emitting fluorescence Tb@Zn-MOF (18) by the encapsulation of the $\mathrm{Tb}^{3+}$ into $\mathrm{Zn}-\mathrm{MOF}\left\{\left[\mathrm{Zn}_{4^{-}}\right.\right.$ $\left.\left.\left(\mathrm{L}^{3-}\right)_{2}\left(\mathrm{O}^{2-}\right)\left(\mathrm{H}_{2} \mathrm{O}\right)_{2}\right] \cdot 4 \mathrm{EtOH}\right\}_{n} \quad\left(\mathrm{~L} 7=4,4^{\prime}, 4^{\prime \prime}-[(1,3,5\right.$-triazine-2,4,6-triyl)tris(sulfanediyl)]tribenzoic acid). Compound 18 exhibited a quenching behavior for $\mathrm{PO}_{3}^{4-}$ detection with a rapid response $(10 \mathrm{~s})$ and a low LOD 

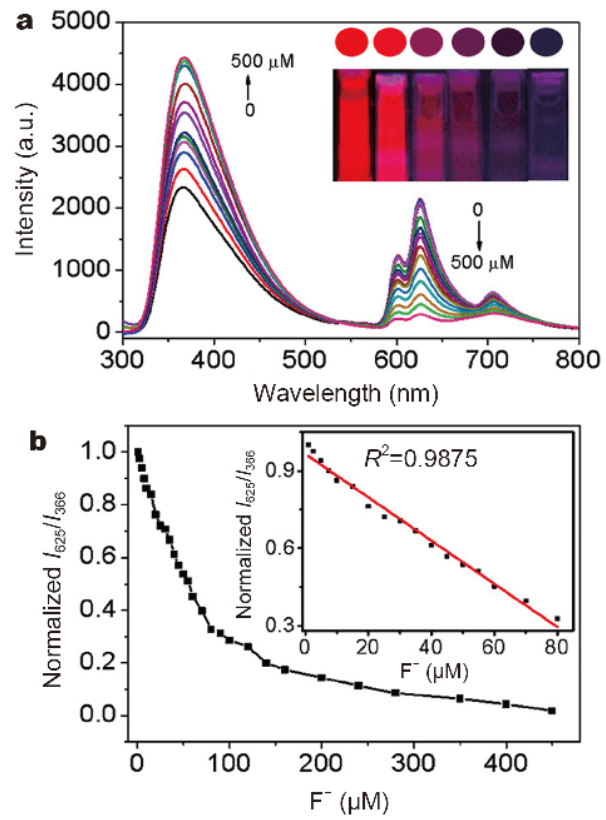

Figure 6 (a) Fluorescence spectra $\left(\lambda_{\mathrm{ex}}=275 \mathrm{~nm}\right)$ of $0.2 \mathrm{mg} \mathrm{mL}^{-1}$ compound 17 upon the addition of fluoride with different concentrations. Inset shows photographs of the mixture solution to illustrate the color and intensity change at different concentrations of fluoride. (b) The plot of the intensity ratio of $I_{625} / I_{366} v s$. fluoride concentration. Reprinted with permission from Ref. [63]. Copyright 2017, American Chemical Society.
(0.1 ppm) (Fig. $7 \mathrm{a}$ and $\mathrm{b})$, attributed to the weak interactions between $\mathrm{PO}_{3}{ }^{4-}$ and $\mathrm{Tb}^{3+}$. It should be noted that the relative ratios of fluorescence intensities $\left(I_{\mathrm{L}} / I_{\mathrm{Tb}}\right)$ respond linearly to the concentration of $\mathrm{PO}_{3}^{4-}$ (Fig. $7 \mathrm{c}$ and d).

\section{Sensing of nitro-aromatic explosives}

Explosives are not only extremely destructive but are also seriously harmful to human's health and environment. Nitrobenzene is the simplest and basic constituent of explosives. The way to quickly and quantitatively detect nitro-aromatic compounds has drawn a lot of attraction [65-67]. Recently, some LMOFs have been constructed for the detection of the nitro-aromatic explosives. The "turn-off" or "turn-on" response arising from the $\pi-\pi$ interactions, binding reaction, photo-induced electron or energy transfer between MOF and analytes can be usually considered as the luminescent mechanism for the sensing process of MOF-based sensors [28,68-73].

Evidently, the pore size and host framework structure of MOFs have a huge impact on the luminescence properties. The first MOF towards the sensing of the explosives was reported by Li's group in 2009 [74]. A microporous MOF, $\left[\mathrm{Zn}_{2}(\mathrm{bpdc})_{2}(\right.$ bpee $\left.)\right]\left(19, \mathrm{bpdc}=4,4^{\prime}\right.$ biphenyldicarboxylate, bpee $=1,2$-bipyridylethene), was
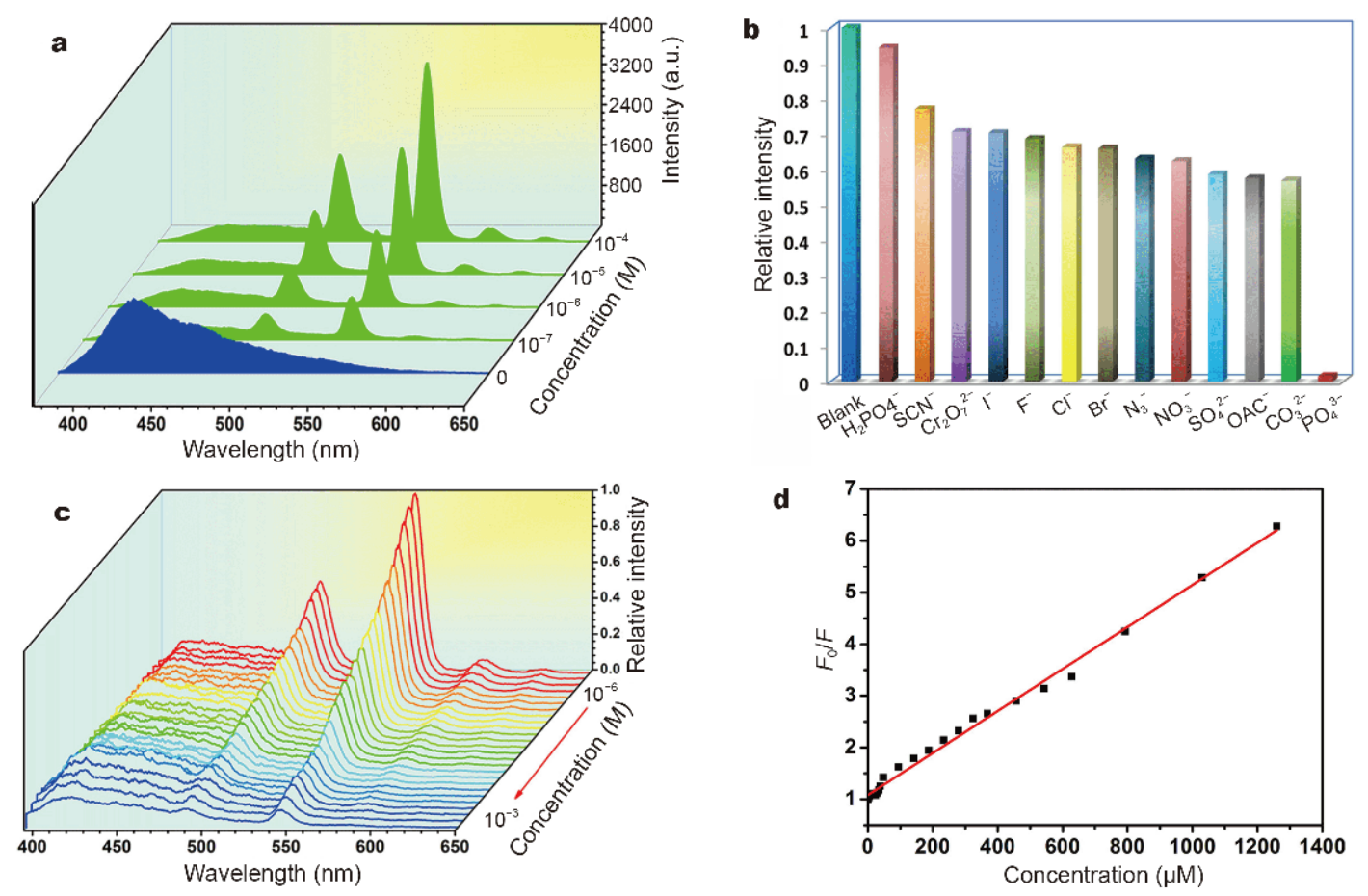

Figure 7 (a) Emission spectra of 18 with $\mathrm{Tb}^{\mathrm{III}}$ at $10^{-4}, 10^{-5}, 10^{-6}, 10^{-7}$, and $0 \mathrm{~mol} \mathrm{~L}^{-1}\left(\lambda_{\text {ex }}=358 \mathrm{~nm}\right)$. (b) Relative fluorescent intensities of ${ }^{5} \mathrm{D}_{0}-{ }^{7} \mathrm{~F}_{2}$ at $545 \mathrm{~nm}$ for 18 dispersed in an aqueous solution containing various anions when excited at $358 \mathrm{~nm}$. (c) Luminescence spectra of 18 under different concentrations of $\mathrm{PO}_{4}^{3-}$ aqueous solutions. (d) The plot of the $K_{\mathrm{SV}}$ curve between the luminescence intensity and $\mathrm{PO}_{4}^{3-}$ concentration in an aqueous solution. Reprinted with permission from Ref. [64]. Copyright 2018, American Chemical Society. 
prepared to detect the 2,4-dinitrotoluene (DNT) and 2,3dimethyl-2,3-dinitrobutane (DMNB) explosives with high sensitivity, fast response, and reversible regeneration capacity. In this system, the microporous structure of 19 was beneficial to increasing the $\pi-\pi$ interactions between aromatic centers of ligands and analytes. Meanwhile, the special 3D structure exposed a lot of sites to bond with analytes, and thereby leading to fluorescence quenching by the electron transfer from MOFs to analytes. All results indicated that MOFs, composed of highly conjugated and electron-rich ligands, have been effectively utilized to sense the nitro-aromatic explosives and related electron-deficient targets by emission quenching.

The luminescent MOFs can be designed through tuning the pore sizes and electronic structures to target the suitable host-guest interactions for explosive sensing applications. $\mathrm{Bu}$ and co-workers [75] used another 3D MOF $\left[\mathrm{NH}_{2}\left(\mathrm{CH}_{3}\right)_{2}\right]_{2}\left[\mathrm{Cd}_{17}(\mathrm{~L} 8)_{12}\left(\mu_{3}-\mathrm{H}_{2} \mathrm{O}\right)_{4}(\mathrm{DMF})_{2}\left(\mathrm{H}_{2} \mathrm{O}\right)_{2}\right]$. solvent (Fig. 8a) (20, $\mathrm{H}_{3} \mathrm{~L} 8=$ 2,4,6-tris[1-(3-carboxylphenoxy)yl-methyl]mesitylene) to probe the electron- deficient nitro-aromatic explosives in solution or vapor, including nitrobenzene (NB), 1,4-dinitrobenzene, 1,3-dinitrobenzene, and 2,4-dinitrotoluene. (Fig. $8 \mathrm{~b}$ and c). The electron-rich L8 ligand of $\mathbf{2 0}$ was beneficial to enhancing its sensitivity. The results revealed that the LOD of nitrobenzene was as low as $0.135 \mathrm{ppm}$ and the luminescent intensity was nearly completely quenched (92.5\%). Additionally, compound $\mathbf{2 0}$ can be regenerated by simple thermal treatments (Fig. 8d). It was proposed that the strong quenching was put down to electron transfer from electron rich ligand to electron withdrawing nitroaromatic explosives. The authors found that the wonderful dispersion of $\mathbf{2 0}$ in DMF solution could bring about the fluorescence quenching with high efficiency.

Recently, a novel bi-functionalized $\mathrm{Zn}(\mathrm{II})$-based MOF stemming from $\mathrm{N}$-rich ligand (Hatz) and conjugated- $\pi$ ligand (NDC) was synthesized to probe NB by Liu and co-workers [76]. For this compound, $\left[\mathrm{H}_{2} \mathrm{~N}\left(\mathrm{CH}_{3}\right)_{2}\right]$. $\mathrm{Zn}(\mathrm{NDC})(\mathrm{atz}) \cdot \mathrm{H}_{2} \mathrm{O} \quad(\mathbf{2 1}, \quad \mathrm{NDC}=2,6$-naphthalenedicarboxylic acid, Hatz $=1 \mathrm{H}$-tetrazol-5-amine), the NDC
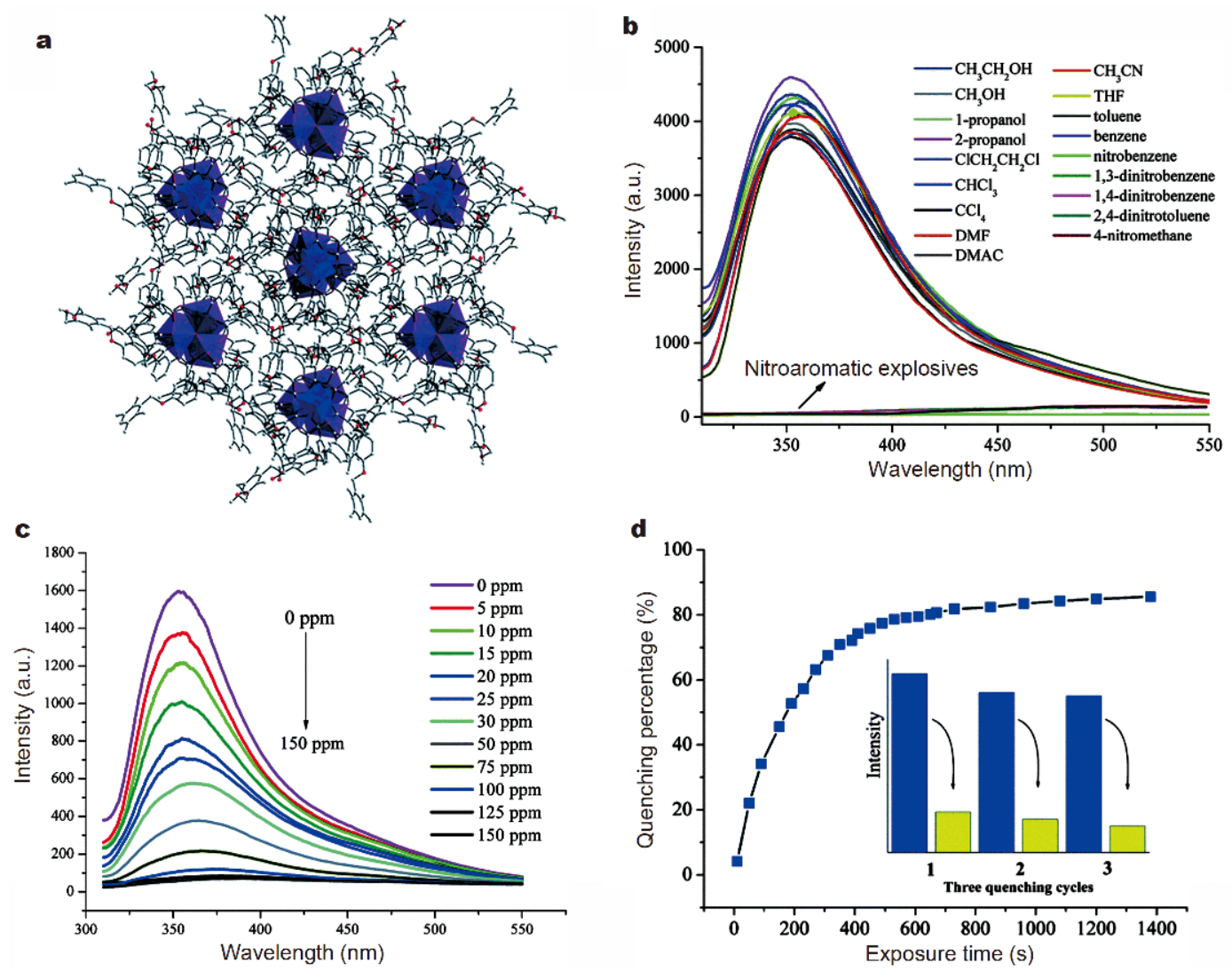

Figure 8 (a) Schematic view of the 3D framework of 20. (b) Emission spectra of 20 dispersed in DMF with the addition of 4000 ppm different organics. (c) Fluorescence titration of compound 20 dispersed in DMF with the addition of different concentrations of nitrobenzene. The excitation wavelength was $290 \mathrm{~nm}$ and fluorescence emission was monitored from 310 to $550 \mathrm{~nm}$. (d) Fluorescence quenching percentage by nitrobenzene vapor. Inset: the results for three continuous quenching cycles. Reprinted with permission from Ref. [75]. Copyright 2014, Royal Society of Chemistry. 
linker efficiently promoted the luminescence of $\mathbf{2 1}$ in the presence of electron-withdrawing analytes. It was found that 21 displayed a luminescence quenching behavior with extremely high sensitivity for detecting nitrobenzene in solution because of the electron transfer and competition absorption of excitation energy between nitrobenzene and MOF. Especially, after detecting nitrobenzene explosive, the framework was still unscathed as proven by powder X-ray diffraction (PXRD). Later, Deng et al. [77] used tetraphenylethylene derivative as the ligand to construct a new MOF $\mathrm{Zn}_{2}\left(\mathrm{H}_{2} \mathrm{~L} 9\right)_{2}\left(4,4^{\prime}\right.$ $\mathrm{BPY})_{2}\left(\mathrm{H}_{2} \mathrm{O}\right)_{3} \cdot \mathrm{H}_{2} \mathrm{O}\left(\mathbf{2 2}, \mathrm{L} 9=4,4^{\prime}, 4^{\prime \prime}, 4^{\prime \prime \prime}-(1,4-\right.$ phenylenebis(2-phenylethene-2,1,1-triyl)tetrabenzoic acid). It exhibited a high selectivity and sensitivity as well as a low LOD of $0.49 \mu \mathrm{mol} \mathrm{L}^{-1}(\sim 110 \mathrm{ppb})$ for detecting 2,4,6trinitrophenol (TNP) by the "turn-off" response. The authors also proposed that four factors, including the photo-induced electron transfer (PET), fluorescence resonance energy transfer (FRET), spectral overlap between the absorption spectrum of TNP and the emission spectrum of the MOF, the interactions between 4,4'-BPY linker and TNP, might give rise to the fluorescence quenching and high selectivity for TNP.

The first self-calibrated MOF-based sensor for TNP detection was reported by $\mathrm{Du}$ and co-workers [78]. Rhodamine 6G (Rh6G) was introduced into an anionic framework $\left\{\left(\mathrm{NH}_{2} \mathrm{Me}_{2}\right)\left[\mathrm{Zn}_{3}\left(\mu_{3}-\mathrm{OH}\right)(\mathrm{tpt})(\mathrm{TZB})_{3}\right](\mathrm{DMF})_{12}\right\}_{n}$ (23, tpt $=2,4,6$-tri $\left(4\right.$-pyridyl)-1,3,5-triazine, $\mathrm{H}_{2} \mathrm{TZB}=4$ (1H-tetrazol-5-yl)benzoic acid) to form a dual emitting material Rh6G@23 that can selectively probe trace amounts of 2,4,6-trinitrophenol (TNP) in the presence of other competitive nitro-aromatic molecules (Fig. 9). In this process, the electrostatic interactions between TNP and the Lewis basic $\mathrm{N}$ atom from ligands as well as surface of the MOF can induce the change of its fluorescence properties.

The fluorescence enhancement (turn-on) MOF-based sensor for the detection of explosives was investigated. Rouhani et al. [79] reported three luminescent MOFs TMU-40(Zn), TMU-40(Cd), and TMU-40(Co), using the 5,6-di(pyridin-4-yl)-1,2,3,4-tetrahydropyrazine ligand (L10) with an aggregation-induced emission (AIE) property and $\mathrm{H}_{2} \mathrm{BDC}$ ligands. These MOFs exhibited excellent capabilities to detect energetic phenol derivatives caused by the "turn-on" process. Respectively, three AIE-MOFs exhibited different fluorescence behaviors. The TMU-40(Co) with unfilled d outer-shells showed a low luminescent quantum yield of $11.69 \%$ through strong LMCT, while the other two MOFs, with filled d outershells, showed strong emission behavior with quantum yields of $38.2 \%$ for TMU- $40(\mathrm{Zn})$ and $31.17 \%$ for TMU$40(\mathrm{Cd})$, respectively. It was found that the phenol derivatives as explosives were efficiently detected with low LOD because both the phenolic hydrogen of analytes can form hydrogen bonding with $\mathrm{N}$ and $\mathrm{O}$ atom of the ligand. Meanwhile, the $\pi-\pi$ interactions between the phenol and the electron-poor ring of $\mathrm{H}_{2} \mathrm{BDC}$ led to the rigidity of the MOF framework to increase the fluorescence intensity (Fig. 10).

\section{Sensing of VOCs}

Among the various detectable analytes, VOCs as the
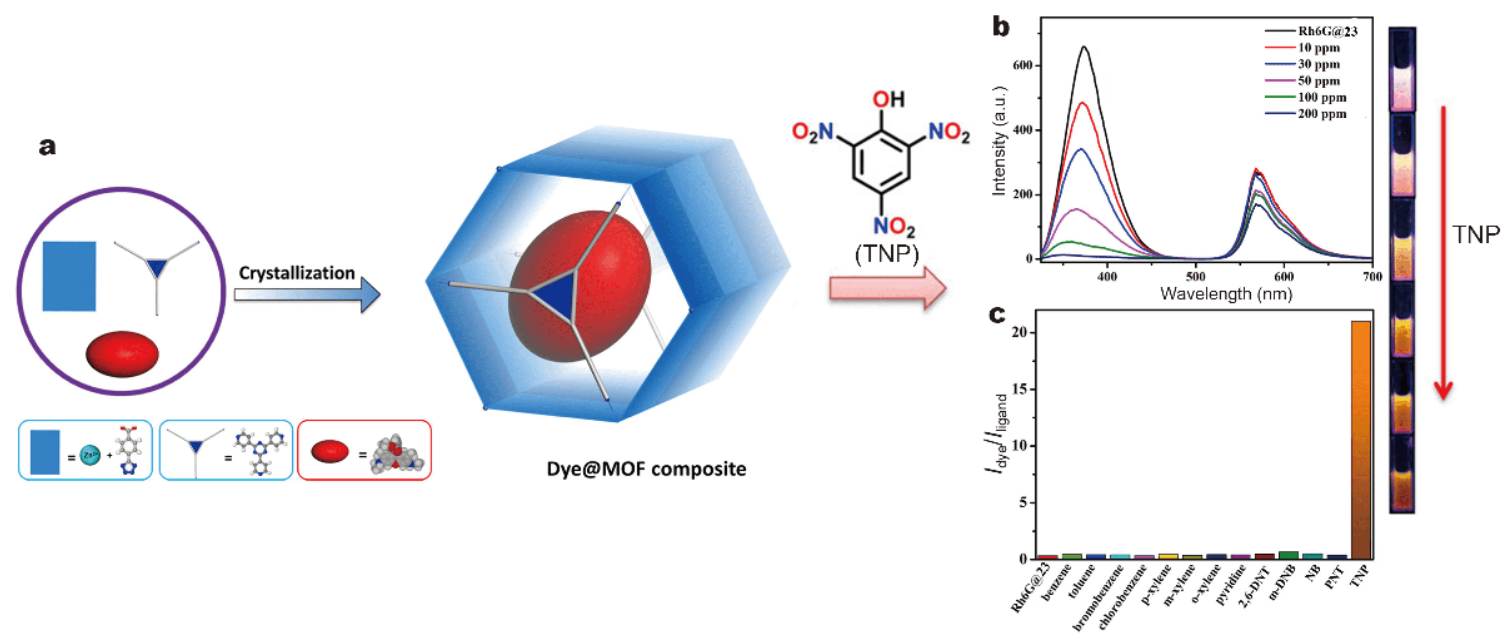

Figure 9 (a) Fabrication of Dye@MOF composite via the "Bottle Around Ship" approach. (b) Emission spectra for Rh6G@23 at different concentrations of TNP (inset: the color changes for Rh6G@23 dispersed in solution at different levels of TNP). (c) The peak-height ratio of dye to ligand after addition of $200 \mathrm{ppm}$ of various analytes. Reprinted with permission from Ref. [78]. Copyright 2018, American Chemical Society. 

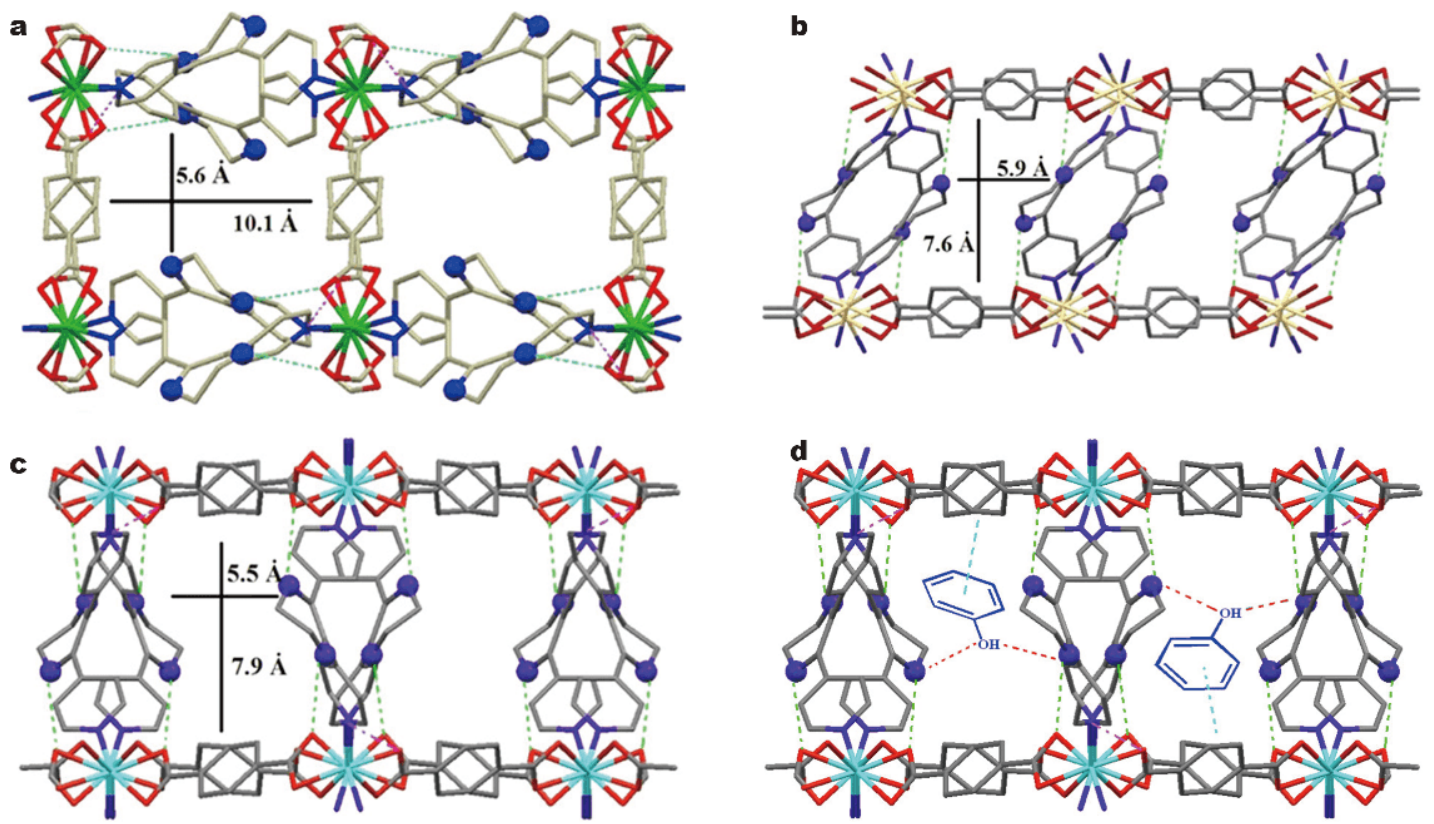

Figure $10(\mathrm{a}-\mathrm{c})$ Schematic views of the structure, pore size, and hydrogen bonding of TMU-40 ( $\mathrm{Zn}$, Cd, and Co are a, b, and c, respectively). (d) Proposed mechanism and schematic view of the binding site for interactions of phenol derivatives by TMU-40. Hydrogen bonding and $\pi-\pi$ interactions of MOF and guest are presented in red and cyan, respectively. Reprinted with permission from Ref. [79]. Copyright 2018, American Chemical Society.

common toxic air/water pollutants (such as aromatic compounds including benzene and derivatives) can cause the chronic health risk to human beings and pose severe environmental threat, climate change as well as the destruction of ozone layer [23,80-87]. The sensors for VOCs usually have two distinct response manners, either the shift of emission spectra or the change of the luminescent intensity for the different VOC-exposed phases [88-90]. As a family of porous materials with great structural diversification and functional tunability, LMOFs have been employed as the promising sensors for detecting VOCs in solution and vapor-phase media because of their regulable host framework towards structure and luminescent property contributed to improving the guests capture capacity and convertible interactions between the framework and analytes. In 2009, $\mathrm{Li}$ and coworkers [91] reported a $\mathrm{Zn}-\mathrm{MOF}, \mathrm{Zn}_{2}(\mathrm{bpdc})_{2}$ (bpee), (24, bpdc $=4,4^{\prime}$-biphenyldicarboxylate, bpee $=1,2$-bipyridylethene), as a sensor for benzoquinone (BQ) via a "turn-off" process. When this compound exposed to the BQ vapor, $94 \%$ of its luminescent intensity was quenched due to the electron transfer. This fluorescence behavior was completely reversible.

On the contrary, some MOF-based sensors with "turnon" fluorescence response have been developed for sensing VOCs $[92,93]$. In order to achieve "turn-on" sensors with lower LOD, many researchers utilized the chromophore tetraphenylethene (TPE)-based ligands that were regarded as one of the most accessible and the simplest AIE luminogens (AIEgens) to synthesize LMOFs [94]. For example, a TPE-based ligand DPEB (DPEB $=4,4^{\prime}-(2,2$ diphenylethene-1,1-diyl) dibenzoic acid) was chosen to fabricate a 2D MOF (NUS-1) for detecting VOCs [95]. In the framework of NUS-1, the two dangling phenyl rings of DPEB ligand were observed to influence the fluorescence enhancement response. When activated NUS-1a was soaked in various VOCs, the quantum yield of NUS-1a distinctly increased (34\%) and the emission wavelength showed a maximum red-shifted emission of $18 \mathrm{~nm}$ in benzene solution, which was attributed to the interactions between the analytes and the dangling phenyl rings.

Later, Zhao et al. [96] reported another TPE-based MOF with a 1D hexagonal channel. They used the 1,1,2,2tetrakis(4-(pyridin-4-yl)phenyl)ethene (tppe) and 4,4'biphenyldicarboxylate $\left(\mathrm{H}_{2} \mathrm{bpdc}\right)$ as the linkers and $\mathrm{Cd}^{2+}$ cations to construct a "turn-on" LMOF $\left[\mathrm{Cd}_{2}(\right.$ tppe)(bpdc) $\left.)_{2}\left(\mathrm{H}_{2} \mathrm{O}\right)\right]$ (25). In 25, the hexagonal channel of the framework not only restricted the rotation of phenyl rings of TPPE ligand but also increased the adsorption ability of aromatic VOCs. Compared with the pristine MOF, the emission of the solvent-free molecules 25a exhibited an obvious shift of about $40 \mathrm{~nm}$ and the quantum yield in- 
creased to $63.3 \%$ (vs. $53.8 \%$ in 25 ). All these results illustrate that the electronic interactions between guest molecules and the dangling phenyl rings of TPPE ligand can change the fluorescence properties of $\mathbf{2 5}$, which are in favor of the analytes sensing. Whereas, after soaking in various VOCs, 25a $\supset$ mesitylene showed a maximum emission hypsochromic shift of $31 \mathrm{~nm}$ owing to mesitylene tending to lock the phenyl rings in a perpendicular conformation to decrease the degree of $\pi$-conjugation of 25 [23,97,98] (Fig. 11). Recently, Du and co-workers [99] constructed a MOF by the assembly of $\mathrm{Tb}^{3+}$ metal ions, $\mathrm{H}_{2}$ oba [4,4'-oxybis(benzoic acid)] as well as Hatz (3amino-1,2,4-triazole) to realize the sensing of $p$-xylene (PX). This MOF exhibited a significant fluorescence enhancement due to the photo-induced electron transfer from $p$-xylene to the $\mathrm{H}_{2} \mathrm{oba}$ ligand.

A luminescent sensor Zr-BTDB-fcu-MOF (BTDB = 4,4'-(benzoic]i1,2,5]thiadiazole-4,7-diyl)dibenzoic acid) with a $\pi$-conjugated organic ligand was used to detect amines. The framework exhibited a rapid "turn-on" response under a low concentration, which was assigned to the hydrogen bonding interactions between the linker and the hosted amines. Detailed mechanistic studies showed that the hydrogen bonding prevented the rotation of thiadiazole to reduce fluorescence behavior [100]. Very recently, Zhao et al. [101] designed a white-light-emitting trichromatic MOF composite by encapsulating greenemitting $\left[\mathrm{Ir}\left(\mathrm{CF}_{3}-\mathrm{ppyF}_{2}\right)_{2} \text { (bpy) }\right]^{+}$and red-emitting $[\mathrm{Ru}-$ $\left.(\text { bpy })_{3}\right]^{2+}\left(\mathrm{CF}_{3}-\right.$ ppyF $_{2}=5$-(trifluoromethyl)-2-(2,4-difluorophenyl)pyridine, bpy $=4,4^{\prime}$-bipyridine) into a blueemitting $\mathrm{Zn}-\mathrm{MOF} \quad\left(\mathrm{Me}_{2} \mathrm{NH}_{2}\right)\left[\mathrm{Zn}_{2}(\mathrm{~L} 10)\left(\mathrm{H}_{2} \mathrm{O}\right)\right] \cdot 4 \mathrm{DMA}$ (26; $\mathrm{H}_{5} \mathrm{~L} 10=2,5$-(6-(3-carboxyphenylamino)-1,3,5-triazine-2,4-diyldiimin-o)-diterephthalic acid) (Fig. 12a). The composite was applied as a multi-dimensional ratiometric probe to detect fluorobenzene by naked eyes (Fig. 12b and c). Obviously, when the composite was exposed to fluorobenzene vapors, the color changed from white to orange. A 2D code identification method can be mapped out to probe analytes by the changes of relative fluorescent intensity (Fig. 12d). This work provides a new strategy to design low-cost and facile chemical sensors.

\section{Sensing of small molecules}

The identification and detection applications of MOFs based on novel structures and luminescent properties have gradually expanded from the detection of ions to small molecules in recent years [19,30,37,102-104]. For example, Bai et al. [105] provided a 2D Cu-MOF with $1.2 \mathrm{~nm} 1 \mathrm{D}$ channels, formulated as $\mathrm{Cu}_{6} \mathrm{~L}_{1} 1_{6} \cdot 3\left(\mathrm{H}_{2} \mathrm{O}\right)$ $(\mathrm{DMSO})(27, \mathrm{~L} 11=5,6$-diphenyl-1,2,4-triazine-3-thiol,
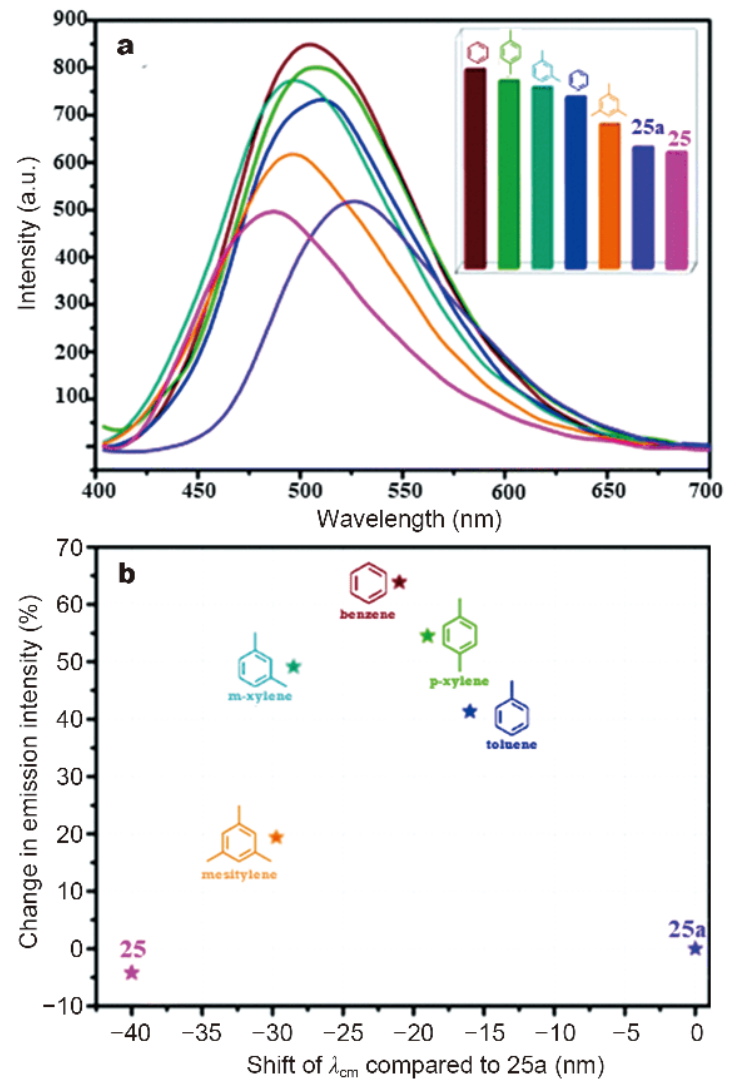

Figure 11 (a) Emission spectra of the as-synthesized 25, 25a and 25a $\supset$ guest molecules, excited at $380 \mathrm{~nm}$; inset: luminescent intensities of 25, 25a and 25a Jguest molecules. (b) The relationship of luminescent intensities of 25a $\supset$ guests versus emission wavelength shift compared to 25a. Reprinted with permission from Ref. [96]. Copyright 2016, Royal Society of Chemistry

DMSO = dimethyl sulfoxide). It was found that this small pore could enhance the $\pi-\pi$ stacking and $\mathrm{C}-\mathrm{H}-\pi$ interactions with the aromatic guest molecules to improve the selective sorption ability for analytes. 27 also displayed good selectivity and strong quenching response to benzene and toluene. A robust microporous Ln-MOF with open metal sites, $\mathrm{Eu}(\mathrm{BTC})\left(\mathrm{H}_{2} \mathrm{O}\right) \cdot 1.5 \mathrm{H}_{2} \mathrm{O}$ (28), was reported by Chen et al. [106] to detect DMF in 1-propanol emulsion. In the sensing process, the obvious luminescent enhancement for DMF and quenching effect for acetone can be observed. This work showed that the luminescent changes of $\mathbf{2 8}$ were attributed to the coordination interactions between 1-propanol molecules and open Eu sites. With the same mechanism, the first near-infrared microporous luminescent Yb-MOFs, $\mathrm{Yb}(\mathrm{BPT})\left(\mathrm{H}_{2} \mathrm{O}\right)$ $(\mathrm{DMF})_{1.5}\left(\mathrm{H}_{2} \mathrm{O}\right)_{1.25}(29, \mathrm{BPT}=$ biphenyl-3,4',5-tricarboxylate) was fabricated by Guo and co-workers [107]. The solvent-free MOF 29a exhibited high sensitivity and se- 

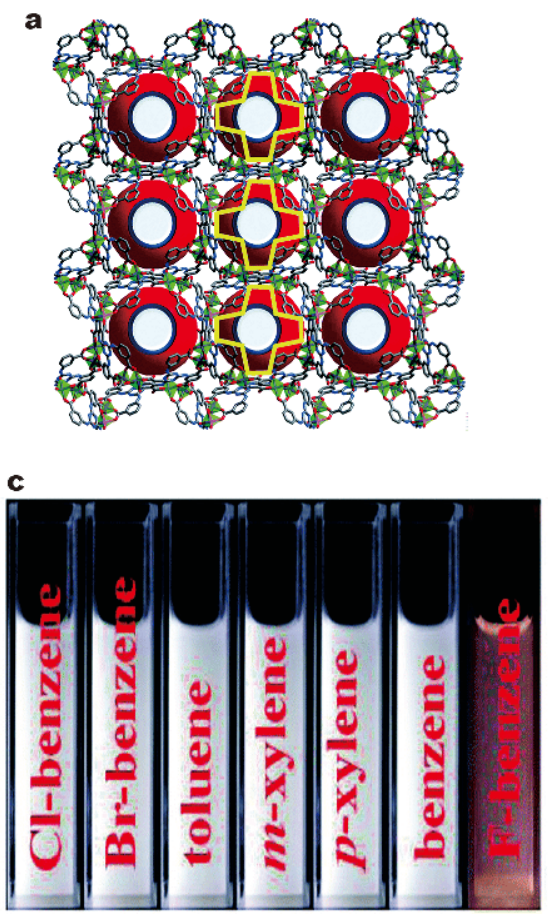
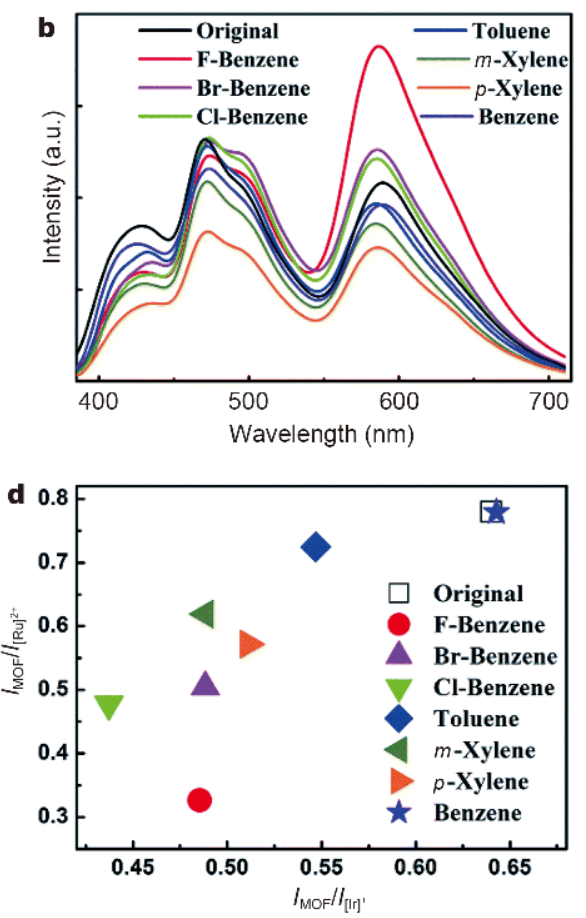

Figure 12 (a) The structure of compound 26. (b) The emission spectra of seven structurally similar aromatic molecules based on two emissionintensity ratios: $I_{\mathrm{MOF}} / I_{[\mathrm{Ir}]}{ }^{+}$and $I_{\mathrm{MOF}} / I_{[\mathrm{Ru}]^{2+}}$. (c) Photographic images of the emulsions of composite in different solvents under UV light irradiation at $365 \mathrm{~nm}$. (d) The corresponding 2D decoded map of seven structurally similar aromatic molecules. Reprinted with permission from Ref. [101]. Copyright 2018, Royal Society of Chemistry.

lectivity towards acetone molecules. Similarly, Xiao and co-workers [108] utilized another framework Tb(BTC).Guest (30) for detecting acetone with a "turn-off" behavior. Unusually, in this system, the absorption band of acetone overlapped that of BTC ligand, which influenced the energy transfer from the BTC to acetone, and then led to quenching effect.

$\mathrm{Ma}$ and co-workers [109] reported a lanthanide-based framework featuring coordinated water molecules, $\left[\mathrm{Eu}_{2}-\right.$ $\left(\mu_{2}\right.$-pzdc $)\left(\mu_{4}\right.$-pzdc $)\left(\mu_{2}\right.$-ox $\left.)\left(\mathrm{H}_{2} \mathrm{O}\right)_{4}\right] \cdot 8 \mathrm{H}_{2} \mathrm{O} \quad\left(31, \mathrm{H}_{2}\right.$ pzdc $=$ 2,5-pyrazinedicarboxylic acid, $\mathrm{H}_{2} \mathrm{Ox}=$ oxalic acid) for detecting acetone via a "turn-off" process at room temperature. Notably, the strong hydrogen bonding between acetone and coordinated water can defend the energy transfer process from linker to $\mathrm{Eu}^{3+}$, leading to a "turnoff" response.

A Tb-based MOF, $\mathrm{Na}\left[\mathrm{Tb}(\mathrm{OBA})_{2}\right]_{3} \cdot 0.4 \mathrm{DMF} \cdot 1.5 \mathrm{H}_{2} \mathrm{O}$ (32, $\mathrm{OBA}=4,4^{\prime}$-oxybis(benzoate)), has been constructed by Lin and co-workers [110]. The solvent-free $\mathbf{3 2}$ was used to recognize $\mathrm{H}_{2} \mathrm{O}$ molecules by fluorescence quenching, assigned to interactions between coordination $\mathrm{Tb}^{3+}$ ions and $\mathrm{H}_{2} \mathrm{O}$ by $\mathrm{O}-\mathrm{H}$ oscillators. Recently, Liu et al. [111] reported a water-stable $\mathrm{MOF},\left[\mathrm{Cd}_{2}(\mathrm{tib})_{2}(\mathrm{bda})_{2}\right] \cdot(\text { solvent })_{n}$
(33, tib $=1,3,5$-tris(1-imidazolyl)benzene, bda $=2,2^{\prime}$-biphenyldicarboxylic acid) (Fig. 13a), which can detect ketones in aqueous solution with a high selectivity and sensitivity. In this system, the stability of $\mathbf{3 3}$ was significantly enhanced in solution due to the double-helical structure formed by dense stacking. When $\mathbf{3 3}$ was immersed in water and some organic solvents such as DMF, DMA, ethanol, methanol, n-propanol, tetrahydrofuran (THF), acetonitrile, dioxane, dichloromethane $\left(\mathrm{CH}_{2} \mathrm{Cl}_{2}\right)$, acetone, methyl isobutyl ketone and cyclohexanone, obvious emission quenching was observed only in ketone solutions (Fig. 13b). In particular, with the increase of acetone concentration to $0.7 \mathrm{vol} \%$, the fluorescence emission of suspension was quenched in aqueous solution (Fig. 13c). The reason is the energy transfer from the excited state of MOF to the LUMO of analytes and competitive absorption of excitation energy between ketone and MOF. In this way, the MOF serves as a potential chemical sensor for small molecules.

Other than the above-mentioned "turn-off" cases, "turn-on" LMOF sensors for probing small molecules have also been reported. Li et al. [112] successfully constructed a novel Ln-MOF, [ $\left.\mathrm{Eu}_{2} \mathrm{~L} 12\left(\mathrm{H}_{2} \mathrm{O}\right)_{4}\right] \cdot 3 \mathrm{DMF}$ (34, 


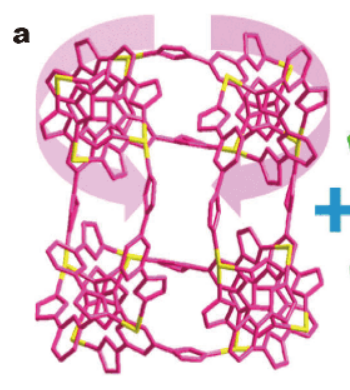

(1)

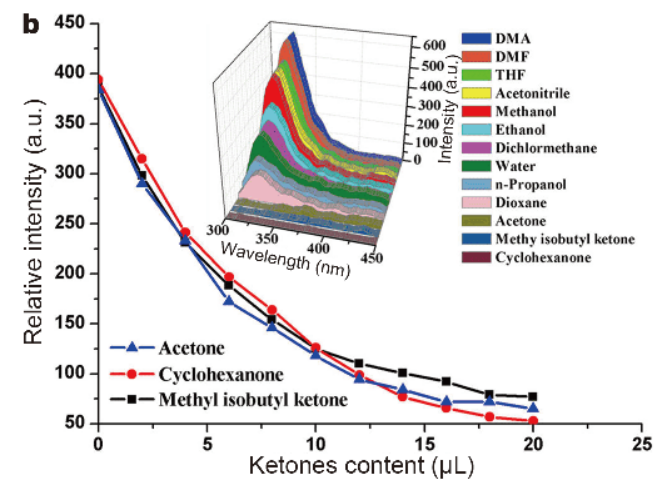

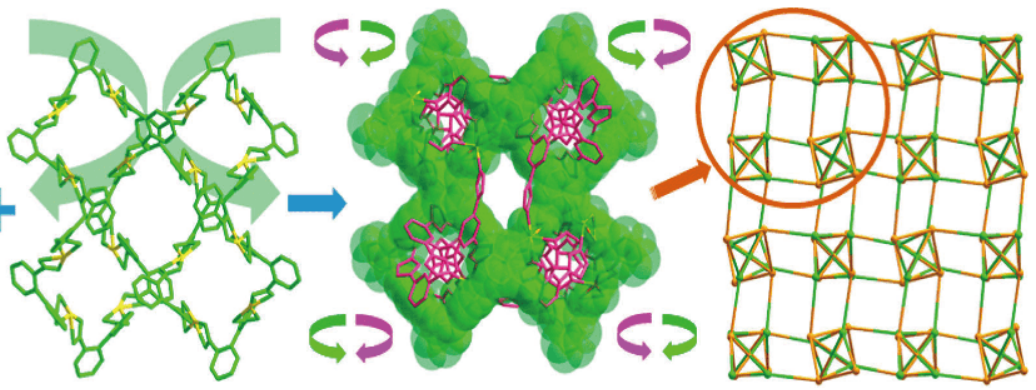

(3)

(4)

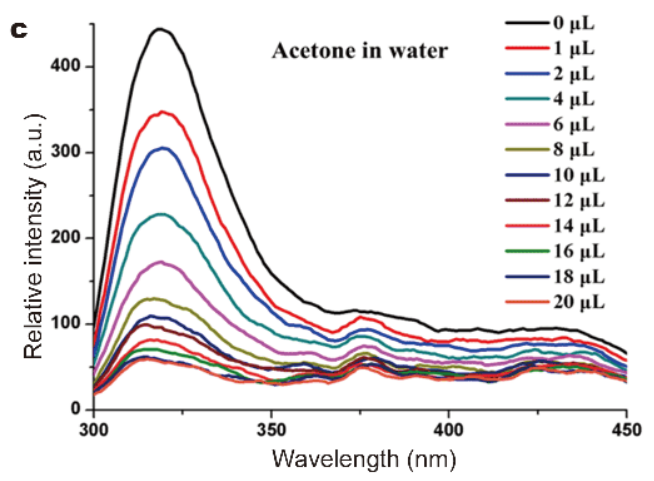

Figure 13 (a) The helical chain framework assembled by coordination interactions of $\mathrm{Cd}^{2+}$ ions with tib and bda ${ }^{2-}$ ligands, respectively. (b) The quenching efficiencies of emission $(325 \mathrm{~nm})$ of 33 along with the gradual addition of ketones, $\lambda_{\text {ex }}=275 \mathrm{~nm}$. The inset represents the fluorescent emission of 33 dispersed in different solvents. (c) Fluorescent titration of 33 dispersed in water $\left(1 \mathrm{mg} \mathrm{mL}^{-1}\right)$ with the gradual addition of acetone, $\lambda_{\mathrm{ex}}=$ $275 \mathrm{~nm}$. Reprinted with permission from Ref. [111]. Copyright 2016, American Chemical Society.

L12 = 2', $5^{\prime}$-bis(methoxymethyl)-[1, $1^{\prime}: 4^{\prime}, 1^{\prime \prime}$-terphenyl]$4,4^{\prime \prime}$-dicarboxylate) for detecting DMF molecules via the fluorescence enhancement process. It was confirmed that the "turn-on" phenomenon of $\mathbf{3 4}$ was attributed to the strong interactions between DMF and organic linkers. The ligand-to-metal energy transfer process was influenced by free DMF and rotational restriction of the phenyl rings motion within linker. Another enhanced fluorescence case for sensing small molecules was demonstrated by Zhu et al. [113] with $\mathrm{Ln}-\mathrm{MOFs}$ [ $\operatorname{Ln}_{2}(\mathrm{fu}-$ marate $_{2}$ (oxalate $\left.)\left(\mathrm{H}_{2} \mathrm{O}\right)_{4}\right] \cdot 4 \mathrm{H}_{2} \mathrm{O}(\mathrm{Ln}=\mathrm{Eu}, \mathrm{Tb})$. It was observed that the fluorescence was significantly quenched after removing water molecules. In particular, it was found that the original structure of these compounds could be reconstructed and the luminescent properties were recovered by rehydration. Konar and co-workers [114] presented a MOF $[\mathrm{Cu}(\mathrm{L} 13)(\mathrm{I})]_{2 n} \cdot 2 n \mathrm{DMF} \cdot n \mathrm{MeCN}$ (35, L13 = 4'-(4-methoxyphenyl)-4,2':6',4"-terpyridine) to realize the probing of small molecules including different solvents, toxic halobenzenes, $N$-heterocycles, amines, and nitro-aromatic explosive vapors with a rapid fluorescence response. In this process, single-crystal-to-single-crystal (SC-SC) phase transition process can be realized and the framework integrity has not been destroyed. More interestingly, this reversible change could be clearly observed by naked eyes and the camera (Fig. 14). All these results demonstrated that the MOF can be applied as a promising detector for sensing small molecules.

\section{Sensing of gases}

It is critically important to precisely probe gas molecules

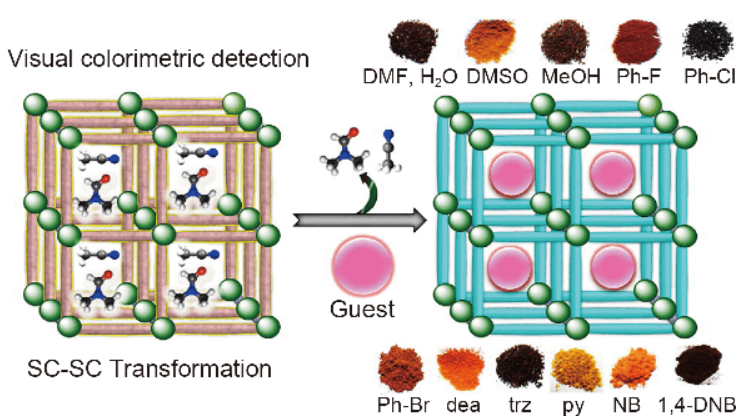

Figure 14 Illustration of guest exchange in $\mathbf{3 5}$ with visible color changes in different solvents, such as halobenzenes, $N$-heterocycles, amines, and nitroaromatic explosives. Reprinted with permission from Ref. [114]. Copyright 2015, American Chemical Society. 
such as $\mathrm{O}_{2}, \mathrm{SO}_{2}, \mathrm{CO}_{2}, \mathrm{H}_{2} \mathrm{~S}, \mathrm{NO}_{x}$, and $\mathrm{NH}_{3}$, for the aspect of environmental monitoring. MOFs as an emerging class of porous materials exhibit great potential for the detection of gases owing to their ultra-high porosity, tailorable structure, special optical property, etc. [115-121]. Most oxygen-sensing MOFs are based on phosphorescent noble metal complexes. Nevertheless, noble metal-free MOFs have recently been shown to have oxygen sensing capabilities. Lin et al. [116] synthesized a highly porous and fluorescent $\mathrm{Zn}$-MOF by the self-assembly of 3,3',5,5'tetramethyl-4,4'-bipyrazole $\left(\mathrm{H}_{2} \mathrm{bpz}\right), 2$-aminoterephthalic acid $\left(\mathrm{H}_{2} \mathrm{abdc}\right)$, and $\mathrm{Zn}^{2+}$ cations to detect $\mathrm{O}_{2}$ molecules. The fluorescence of MAF-X11 was quenched by $96.5 \%$ at 1 bar of $\mathrm{O}_{2}$, which is obviously larger than phosphorescent precious-metal complexes. The sensing efficiency of MAF-X11 towards $\mathrm{O}_{2}$ was not influenced by other components, illustrating the $\mathrm{O}_{2}$ selectivity. The adsorption amount of MAF-X11 for $\mathrm{O}_{2}$ reached $5.9 \mathrm{~cm}^{3}$ (STP) $\mathrm{g}^{-1}$ at 1 bar to illustrate its high $\mathrm{O}_{2}$ permeability. Meanwhile, the framework structure of MAFX11 contributed to the isolation of the fluorophores to avoid self-quenching and give rise to long fluorescence lifetimes, realizing the high fluorescence quenching by $\mathrm{O}_{2}$.

The incorporation of lanthanide ions within MOF has been proposed to promote $\mathrm{O}_{2}$ sensing. Dou and coworkers [117] introduced $\mathrm{Tb}^{3+}$ to two classical MOFs, CPM-5 and MIL-100, to form two luminescent MOF films (MIL-100(In)つ $\mathrm{Tb}^{3+}$ and CPM-5つTb ${ }^{3+}$ ). These MOF composites possessed the promising ability for the fast and reversible detection of $\mathrm{O}_{2}$ derived from energy transfer from the BTC ligand to $\mathrm{Tb}^{3+}$. Furthermore, the sensing performance of MIL-100(In)つ $\mathrm{Tb}^{3+}$ film is almost an order of magnitude higher than that of CPM-5 $\mathrm{Tb}^{3+}$ film, due to the intramolecular energy transfer of MIL100 which is faster than that of CPM- 5 when $\mathrm{Tb}^{3+}$ is sensitized by the same organic ligand.

In some cases, functional organic moieties can be rationally used to adjust the luminescence performance and guest-responsive property of the resulting LMOF. Ghosh and co-workers [118] have incorporated the free monoamine aromatic group into organic ligand to prepare a chemically stable LMOF, UiO-66@ $\mathrm{NH}_{2}$, for detecting nitric oxide (NO) in the aqueous phase, with a high quenching constant $\left(4.15 \times 10^{5} \mathrm{~L} \mathrm{~mol}^{-1}\right)$ and low detection limit $\left(0.575 \mu \mathrm{mol} \mathrm{L}^{-1}\right)$. The strong interactions between the highly diffusive NO and the MOF bearing pendant free amine are responsible for such a notable sensing performance. Zhang and co-workers [119] presented a functionalized nano MOF $\mathrm{Eu}^{3+} / \mathrm{Cu}^{2+} @ \mathrm{UiO}-66-$ $(\mathrm{COOH})_{2}$ to detect $\mathrm{H}_{2} \mathrm{~S}$ in environmental and biological specimens. It was found that the luminescence of $\mathrm{Eu}^{3+}$ was selectively quenched with the presence of $\mathrm{H}_{2} \mathrm{~S}$ due to strong interactions between $\mathrm{Cu}^{2+}$ and $\mathrm{H}_{2} \mathrm{~S}$, but the luminescence of the ligand-centered was enhanced. As a result, this MOF exhibited remarkable selectivity toward $\mathrm{H}_{2} \mathrm{~S}$ with a rapid response within $30 \mathrm{~s}$. Apart from the strategy to introduce lanthanide ions, MOF-polymer mixed-matrix membranes (MMMs) were also used to detect $\mathrm{H}_{2} \mathrm{~S}$. Zhang et al. [120] reported an Al-MIL-53$\mathrm{NO}_{2}$ comprised of the aluminum metal center and 2nitroterephthalic acid $\left(\mathrm{H}_{2} \mathrm{BDC}-\mathrm{NO}_{2}\right)$ ligand. The $\mathrm{MOF}$, Al-MIL-53- $-\mathrm{NO}_{2}$, was used to blend poly(vinylidene fluoride) (PVDF) to form a MOF-based MMMs (Fig. 15a) that could be used to probe $\mathrm{H}_{2} \mathrm{~S}$ in aqueous solution. The response of Al-MIL-53- $\mathrm{NO}_{2}$ MMMs to $\mathrm{H}_{2} \mathrm{~S}$ gas was monitored by measuring the change in intensity of the luminescence signal at $466 \mathrm{~nm}$ (Fig. 15b). A significant increase in luminescence intensity was observed with the introduction of $\mathrm{H}_{2} \mathrm{~S}$ by a flow-through method (Fig. 15c and d). Al-MIL-53-NO $\mathrm{NO}_{2}$ MMMs has a very low LOD and high selectivity for $\mathrm{H}_{2} \mathrm{~S}$ due to the uniform distribution of MOF particles on the membrane, which increased the interactions between the analyte and the framework (Fig. 15e). Chernikova et al. [121] fabricated a stable MOF-based $\mathrm{SO}_{2}$ sensor based on an indium-based MOF, namely MFM-300. The MFM-300 showed a remarkable $\mathrm{SO}_{2}$ detection capacity with a low LOD of about $5 \mathrm{ppb}$ at the low concentrations down to $75 \mathrm{ppb}$, attributed to the hydrogen bonding interactions between $-\mathrm{OH}$ groups from surface or $\mathrm{C}-\mathrm{H}$ groups from the ligand and the $\mathrm{SO}_{2}$, as well as the electrostatic interactions of $\mathrm{SO}_{2}-\mathrm{SO}_{2}$. Besides, the high selectivity of MFM-300 (In) for the detection of $\mathrm{SO}_{2}$ was also found in presence of $\mathrm{CH}_{4}, \mathrm{CO}_{2}$, $\mathrm{N}_{2}$, and $\mathrm{H}_{2}$ (Fig. 16).

\section{Sensing of biomolecules}

MOFs as chemical sensors also exhibit the promising ability in terms of detecting various bio-chemicals such as mycotoxins antibiotics and DNA [122]. Mycotoxin, as secondary metabolites produced by fungus organisms, whose toxicity has been closely linked to poisoning episodes in human being and animals. Recently, a MOFbased biosensor, $\left[\mathrm{Zn}_{2}(\mathrm{bpdc})_{2}(\right.$ tppe $\left.)\right]$ (LMOF-241, tppe = 1,1,2,2-tetrakis(4-(pyridin-4-yl)phenyl)ethene), has been developed by Li and co-workers [123] for probe mycotoxin aflatoxin B1 with an exceptionally high internal quantum yield $(92.7 \%)$ and low LOD of $46 \mathrm{ppb}$. It was demonstrated that the electron transfer from MOF to toxin rather than the energy transfer led to the emission quenching (Fig. 17). Tian et al. [124] reported a novel 
a
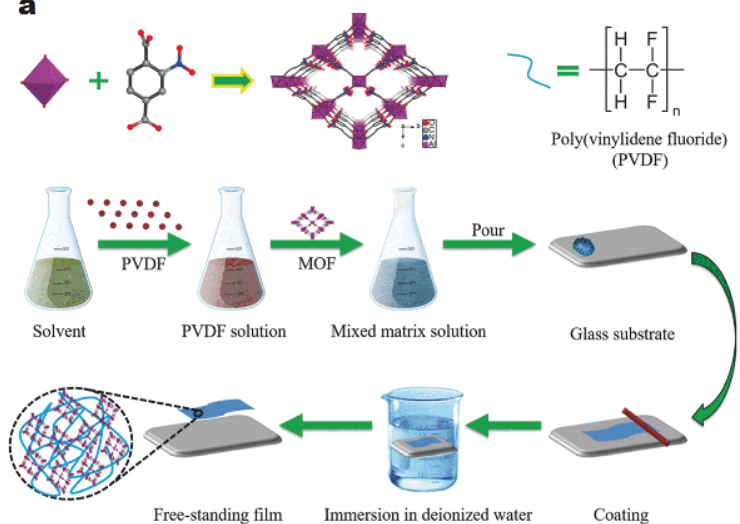

Free-standing film

Immersion in deionized water

Coating
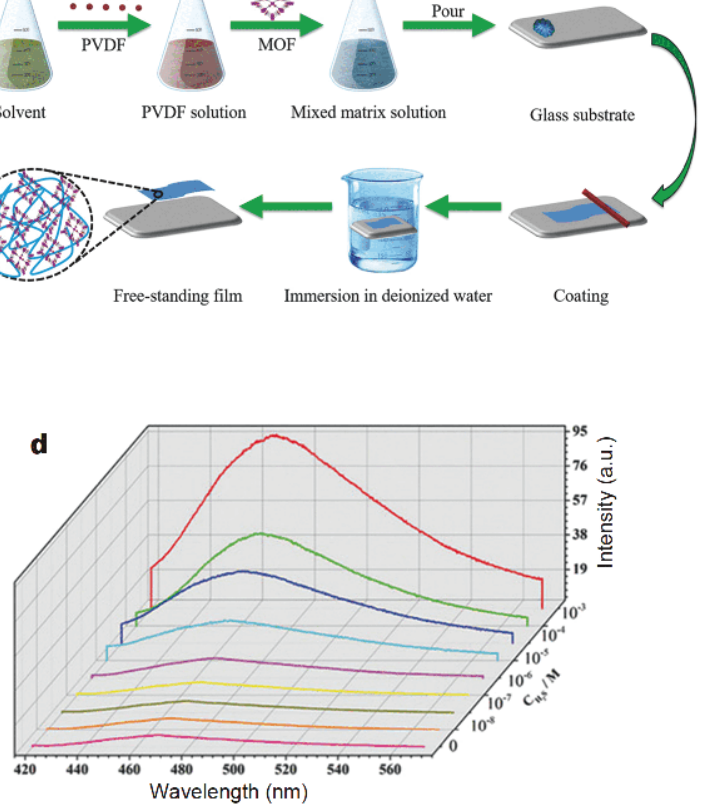

b
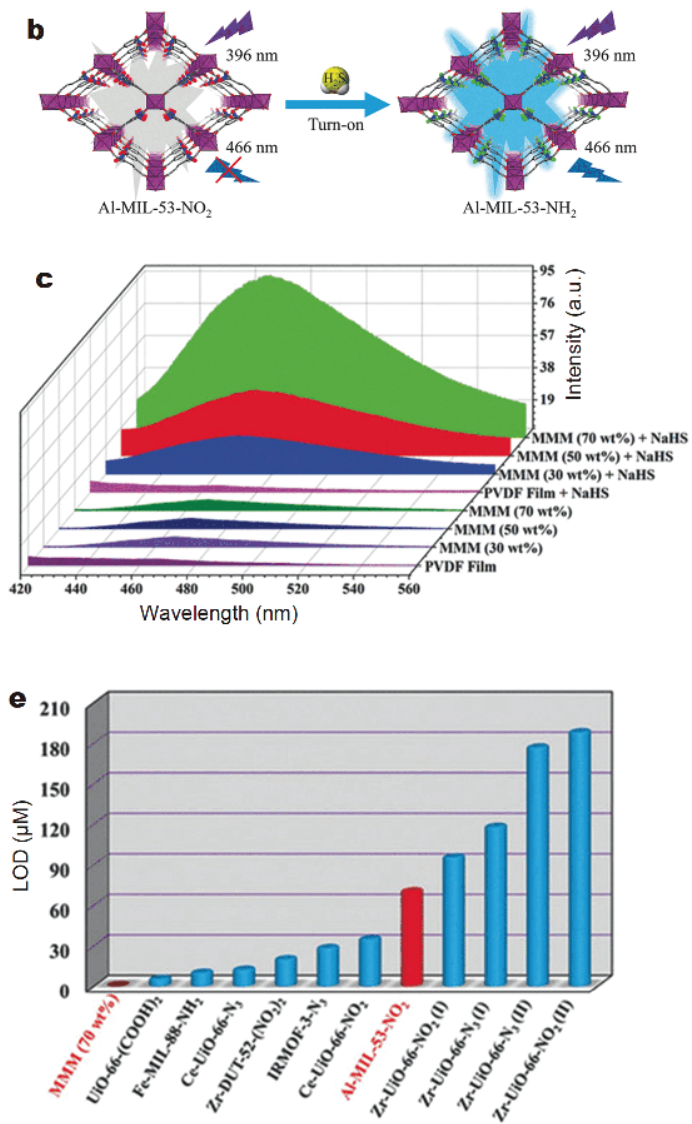

Figure 15 (a) Process for the formation of MOF-based MMMs. (b) Illustration of nitro-functionalized MOF as a fluorescence-based "turn-on" probe for $\mathrm{H}_{2} \mathrm{~S}$. (c) The emission spectra of PVDF membrane, Al-MIL-53- $\mathrm{NO}_{2}$ MMM (30 wt\%), Al-MIL-53- $\mathrm{NO}_{2}$ MMM (50 wt\%), and Al-MIL-53-NO MMM (70 wt $\%)$ upon NaHS $\left(1 \times 10^{-3} \mathrm{~mol} \mathrm{~L}^{-1}\right)$ treatment $\left(\lambda_{\mathrm{ex}}=396 \mathrm{~nm}\right)$. (d) Fluorescence spectra of Al-MIL-53-NO $\mathrm{NMM}_{2}(70 \mathrm{wt} \%)$ with increasing concentrations $\left(0-10^{-3} \mathrm{~mol} \mathrm{~L}^{-1}\right)$ of $\mathrm{H}_{2} \mathrm{~S}$. (e) The limit of detection of the various existing MOFs for the sensing of $\mathrm{H}_{2} \mathrm{~S}$. Reprinted with permission from Ref. [120]. Copyright 2018, Wiley-VCH.

FITC@MOF composite, in which fluorescein isothiocyanate (FITC) was incorporated into $\left[\mathrm{Cd}(\mathrm{L} 14) \cdot\right.$ solvent $_{n}$ (36, L14 = 3,3'-(6-hydroxy-1,3,5-triazine-2,4-diyl)bis(azanediyl)dibenzoic acid) (Fig. 18a) via guest adsorption, to detect 3-nitropropnic acid (3-NPA) as the toxic mycotoxins. In this composite, the microporous structure of 36 efficiently restricted the rotation of FITC molecules, which not only enhanced the output fluorescence intensity by diminishing the aggregation-caused quenching (ACQ) effect (Fig. 18b) but also retained the $\mathrm{pH}$ responsibility for acid mycotoxin. Therefore, the FITC@MOF composite exhibited highly sensitive and selective "turn-off" response with the presence of 3-NPA, along with a low LOD $\left(0.135 \mathrm{~mol} \mathrm{~L}^{-1}\right)$ and excellent recyclability (Fig. 18c and d). It was proposed that 3-NPA could induce the conformational conversion of FITC and then give rise to the fluorescence quenching, driven by fluorescence resonance energy transfer.
Some MOF-based biosensors for detecting DNA were also constructed. Jiang and co-workers [125] fabricated an amine-functionalized $\mathrm{MOF}, \mathrm{UiO}-66-\mathrm{NH}_{2}$, which can detect the single-stranded DNA (ssDNA) with high sensitivity and selectivity via fluorescence enhancement. The "turn-on" phenomenon was observed due to the hydrogen bonding interactions between the amino group in $\mathrm{UiO}-66-\mathrm{NH}_{2}$ and ssDNA. In addition, a sensitively electrochemical sensor for DNA detection based on FeTCPP@MOF composites was constructed by Lei and co-workers [126]. They used HKUST-1 $\left(\mathrm{Cu}_{3}(\mathrm{BTC})_{2}\right)$ as the host to realize the one-step encapsulation of iron(III) meso-5,10,15,20-tetrakis(4-carboxyphenyl) porphyrin chloride (FeTCPP) followed by the conjugation with streptavidin (SA) as a recognition element. As an electrochemical sensor, this material displayed a high selectivity and robustness to detect target DNA with a low LOD of $0.48 \mathrm{fmol} \mathrm{L}^{-1}$, due to the high catalytic activity of 

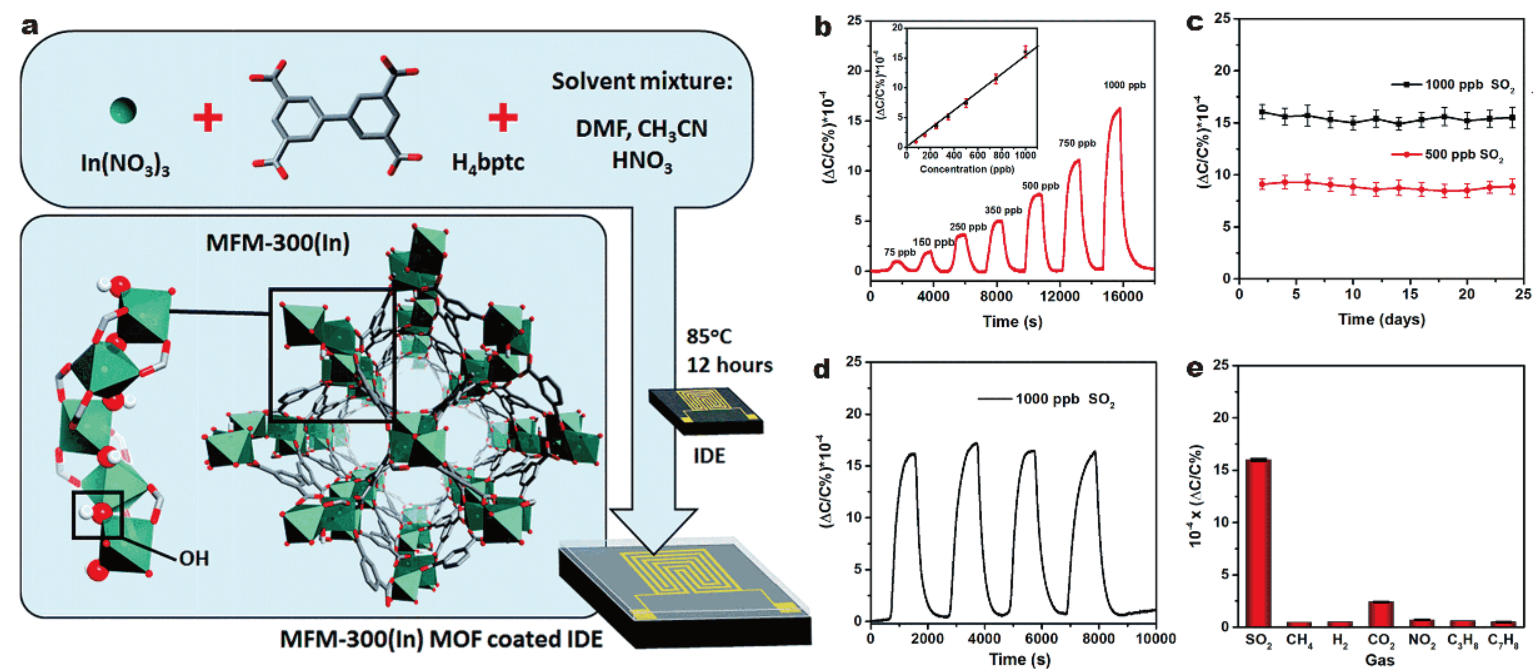

Figure 16 (a) Schematic representation of the optimized solvothermal preparation approach of MFM-300 (In) MOF thin film on the interdigitated electrodes. (b) Detection of $\mathrm{SO}_{2}$ in the 75 to $1000 \mathrm{ppb}$ concentration range, inset: linear response for the corresponding range. (c) Linear response for MFM-300 (In) MOF-based sensor upon exposure to 500 and $1000 \mathrm{ppb}$ of $\mathrm{SO}_{2}$ over 24-day period. (d) Reproducibility cycles for the detection of $1000 \mathrm{ppb}$ of $\mathrm{SO}_{2}$. (e) Selectivity of the MFM-300 (In) MOF sensor to other gases at 1000 ppb. Reprinted with permission from Ref. [121]. Copyright 2018, Royal Society of Chemistry.
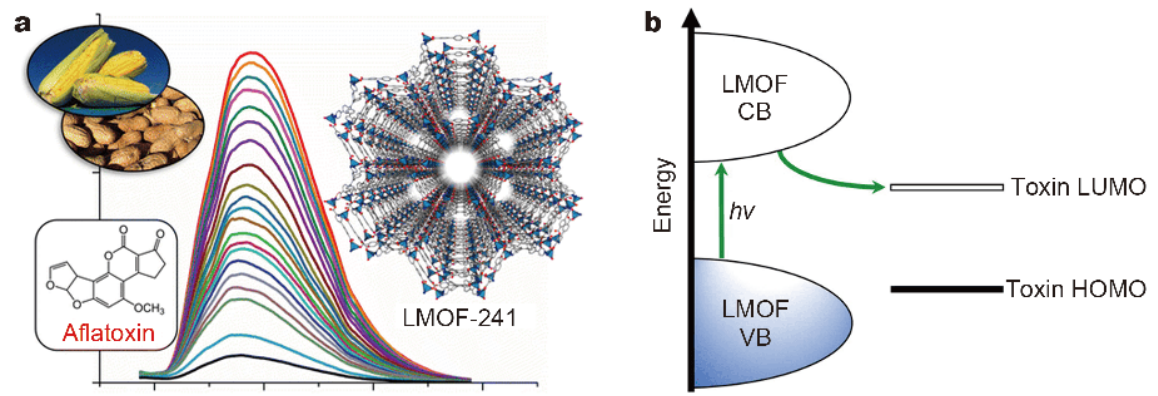

Figure 17 (a) The complete structure of LMOF-241 and emission spectra of LMOF-241 with the incremental addition of AFB1 in DCM. (b) Schematic demonstration of the electron transfer from LMOF-241 to mycotoxin LUMO, resulting in the quenched emission. Reprinted with permission from Ref. [123]. Copyright 2015, American Chemical Society.

FeTCPP and special recognition between SA and aptamer. To minimize the high background fluorescence of DNA-intercalating dyes and increase the detection sensitivity, Fang et al. [127] employed MIL-101 $\left(\mathrm{Cr}_{3} \mathrm{~F}-\right.$ $\left.\left(\mathrm{H}_{2} \mathrm{O}\right)_{2} \mathrm{O}\left[\left(\mathrm{O}_{2} \mathrm{C}\right)-\mathrm{C}_{6} \mathrm{H}-\left(\mathrm{CO}_{2}\right)\right]_{3} \cdot n \mathrm{H}_{2} \mathrm{O}\right)$ as a quenching sensor to probe sequence-specific DNA complex by $\pi-\pi$ stacking and electrostatic interactions. In the sensing process, the background fluorescence of SYBR Green I (SG) significantly reduced. The composite exhibited a high sensitivity and selectivity for probing target DNA with a low detection limit $\left(73 \mathrm{pmol} \mathrm{L}^{-1}\right)$ due to the asformed rigid double-stranded structure of DNA will be far away from the MIL-101 surface and combine with SG dye to enhance its fluorescence.
Recently, Weng and Yan et al. [128] reported a new ratiometric $\mathrm{Ag}^{+} @ \mathrm{Eu}-\mathrm{MOF}$ sensor for detecting aspartic acid, which is served as a major excitatory neurotransmitter in the central nervous system. The $\mathrm{Ag}^{+} @ \mathrm{Eu}-$ complex exhibited a high selectivity towards aspartic acid with the LOD of $4.6 \times 10^{-7} \mathrm{~mol} \mathrm{~L}^{-1}$, along with a good linear relationship between $I_{\mathrm{L}} / I_{\mathrm{Eu}}$ and the aspartic acid. The emission intensity of ligand was enhanced while intensity of $\mathrm{Eu}^{3+}$ was weakened after injection of aspartic acid, and color was changed from light yellow to blue simultaneously. The emission intensity change was driven by fluorescence resonance energy transfer effect between aspartic acid and $\mathrm{Ag}^{+} @ \mathrm{Eu}-\mathrm{MOF}$ indicated by overlap of emission spectrum and $\mathrm{pH}$ influence of incorporation of 

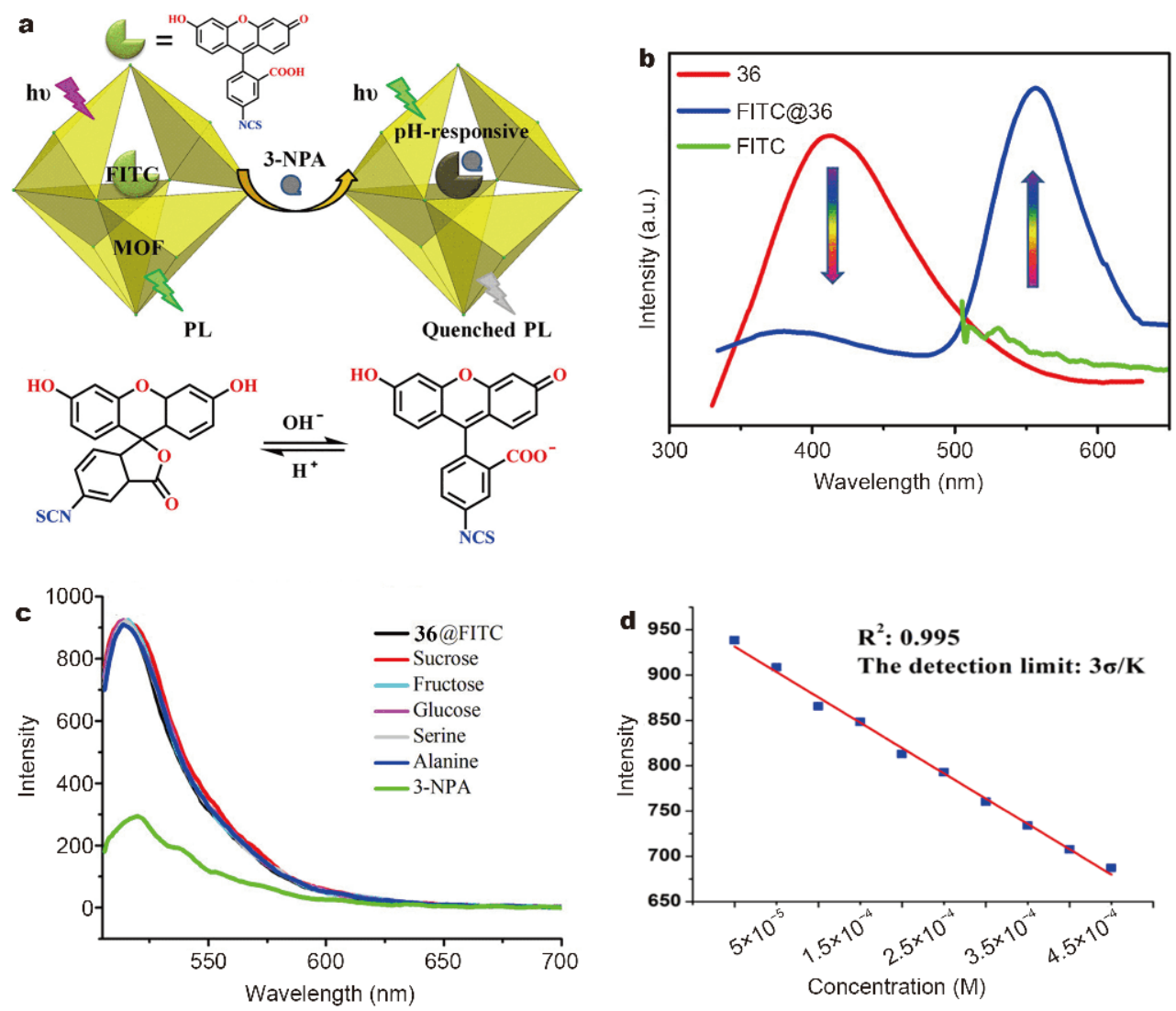

Figure 18 (a) Schematic illustration of the underlying mechanism of the selective sensing of FITC@36 towards 3-NPA. (b) Solid-state emission spectra of 36 and FITC@36 $\left(\lambda_{\mathrm{ex}}=340 \mathrm{~nm}\right)$, FITC $\left(\lambda_{\mathrm{ex}}=490 \mathrm{~nm}\right)$. (c) Emission spectra $\left(\lambda_{\mathrm{ex}}=490 \mathrm{~nm}\right)$ of FITC@36 dispersed in water after addition of five interfering substances $(60 \mu \mathrm{L})$ and a subsequent addition of 3 -NPA $(60 \mu \mathrm{L})$. (d) The detection limit of $0.135 \mathrm{~mol} \mathrm{~L}^{-1}$ calculated via $3 \sigma / k(k$ : slope, $\sigma$ : standard), with a linear fitting ranging from 0 to $4.5 \times 10^{-4} \mathrm{~mol} \mathrm{~L}^{-1}$. Reprinted with permission from Ref. [124]. Copyright 2018, American Chemical Society.

acidic aspartic acid.

Very recently, a ratiometric probe based on Eu-MOF, fabricated from $\mathrm{H}_{2} \mathrm{NDC}$ and $\mathrm{Eu}^{3+}$, was investigated for high-sensitivity sensing of amino acids with a high sensitivity and a low LOD $\left(21 \mu \mathrm{mol} \mathrm{L}{ }^{-1}\right)$. The fluorescent quenching by amino acids was due to the coordination interactions of water molecules, which affected the energy transfer from NDC to $\mathrm{Eu}^{3+}$ [129]. Wang and co-workers [130] also fabricated a series of isostructural mixed-metal Ln-MOFs, comprised of different lanthanide metal ions and the BTC ligand, by tuning the molar ratio of $\mathrm{Tb}^{3+}$ to $\mathrm{Eu}^{3+}$. Among these MOFs, the $\mathrm{Eu}_{0.1} \mathrm{~Tb}_{0.9}$ - $\mathrm{BTC}$ (MLMOF3) was selected to prepare the thin film to detect coumarin (pharmaceutical molecules) (Fig. 19a-c). The hydrogen bonding interactions between coumarin and MLMOF-3 not only affected the energy transfer from ligand to the lanthanide metal, but also tuned the energy allocation between $\mathrm{Eu}^{3+}$ and $\mathrm{Tb}^{3+}$ ions, leading to the decreased intensity at $547 \mathrm{~nm}\left(\mathrm{~Tb}^{3+},{ }^{5} \mathrm{D}_{4} \rightarrow{ }^{7} \mathrm{~F}_{5}\right)$ and the increased intensity at $619 \mathrm{~nm}\left(\mathrm{Eu}^{3+},{ }^{5} \mathrm{D}_{4} \rightarrow{ }^{7} \mathrm{~F}_{2}\right)$ (Fig. 19d). This ratiometric sensor exhibited a high selectivity for coumarin among other targets, and the detection limit was $0.34 \mu \mathrm{g} \mathrm{mL}^{-1}$.

\section{SUMMARY AND PERSPECTIVES}

LMOFs, with tremendous structural diversity and high tunability as well as special optical properties, have been developed as promising agents for chemical sensing of diverse analytes. Summarized here are some of the recent advances in LMOF materials for detecting metal ions and anions, nitrobenzene and nitro-aromatic explosive, VOCs, small molecules and biomolecules to highlight the influence of the components or structures on the sensing performance of LMOFs. Meanwhile, the various luminescent sensing mechanisms and structure-property relationship have also been briefly revealed (Table 1). It has been demonstrated that the coordination environment of metal ions, framework structure, the size and geometry of 

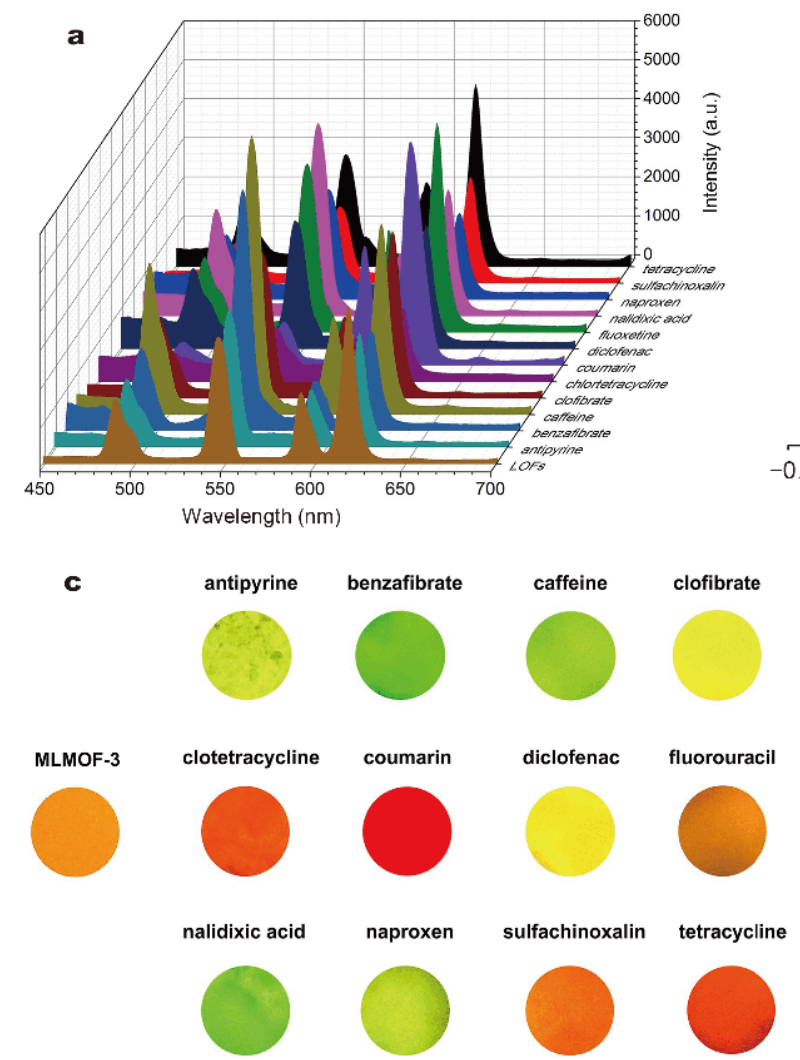
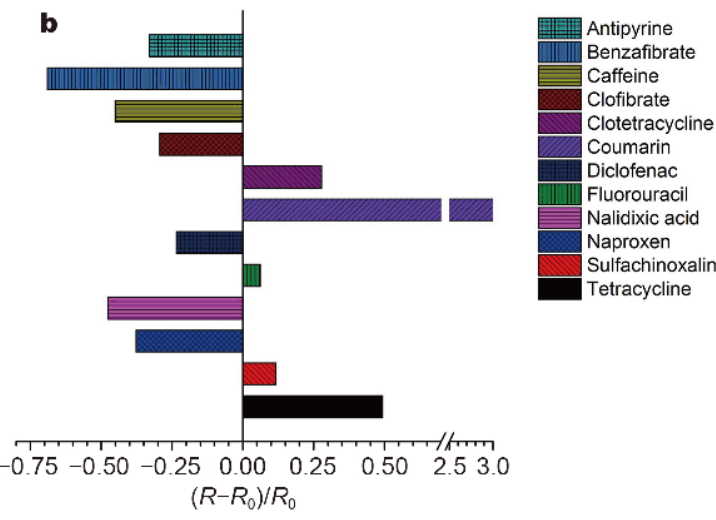

d

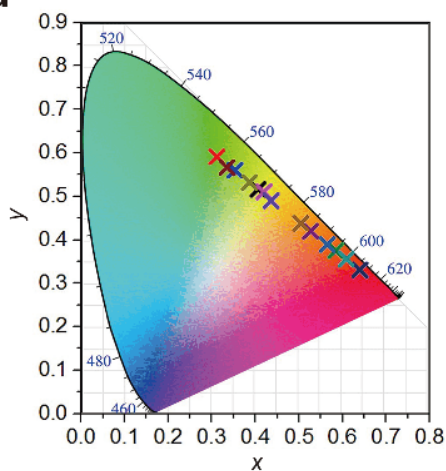

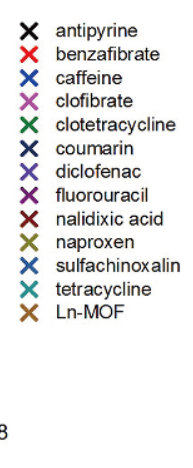

Figure 19 (a) Emission spectra, (b) emission intensity ratio changes, (c) optical photographs and (d) CIE chromaticity coordinates of MLMOF-3 thin film in the presence of different analytes $\left(20 \mathrm{~mL}, 10^{-4} \mathrm{~mol} \mathrm{~L}^{-1}\right)$. Reprinted with permission from Ref. [130]. Copyright 2018, Elsevier.

pore and the interaction with the analytes can cause different luminescent properties of MOFs, which can be monitored easily either by fluorescence changes in terms of intensity/emission frequency or naked eyes. It should be noted that despite significant progress has been made to apply LMOF materials as sensors, there are still many challenges that need to be addressed. For example, when most of the detection processes are based on the "turnoff" processes, "turn-on"-based LMOF materials are more desirable to continuously improve the selectivity and sensitivity. Meanwhile, most of the established LMOF sensors rely on the intensity changes of the luminescence signals derived from single emission center including lanthanide ions, fluorescent ligands, etc. This may give rise to erroneous responses triggered by changes of the external conditions. Therefore, the ratiometric LMOF sensors that utilize the ratio between the intensity of two or multiple emission centers within the same MOF should be further developed to break the main limits of the single emission-based LMOFs. The self-calibrating ability can also endow LMOFs with high selectivity and sensitivity. Then the construction strategy of the ratio- metric sensors based on LMOFs should be developed. The precisely targeted construction methods of LMOFs with desired structure and functionality for sensing application fields should be exploited, which may help scientists to rationally develop LMOF sensors with desired detection performance.

The detection performance of LMOFs as chemical sensors arises not only from their diverse porous structures, but is also driven largely by the synergistic interactions among different subsets including inorganic/ organic component features, guest molecules, etc. As a result, the relationship between the structure and property, host-guest interaction, and synergistic effects should be deeply studied, and experiment investigations combined with theoretical calculations will further accelerate the development of LMOFs. The research of luminescent probes based on MOFs is still on the stage of continuous development. It is anticipated that more efforts from chemists will contribute to the development of LMOFbased chemical sensors following rational design and synthesis principles. The combination of the luminescence sensing and other functions will expand the po- 
Table 1 List of selected LMOFs, organized by sensing application, analyte, and detection mechanism

\begin{tabular}{|c|c|c|c|c|}
\hline Sensing application & MOF & Analyte & Mechanism & Ref. \\
\hline \multirow[t]{11}{*}{ Metal cations } & {$\left[\mathrm{EuL} 1(\mathrm{OH})_{2}\right]\left(\mathrm{NO}_{3}\right) \cdot x($ solvent $)$} & $\mathrm{Fe}^{3+}$ & $\begin{array}{l}\text { Competition absorption of excitation } \\
\text { energy and electronic interactions }\end{array}$ & 39 \\
\hline & {$[\mathrm{ZnL} 2] \cdot x \mathrm{G}$} & $\mathrm{Fe}^{3+}$ & Energy transfer & 40 \\
\hline & $\begin{array}{c}{\left[\mathrm{Cd}_{2} \mathrm{Na}(\mathrm{L} 3)(\mathrm{BDC})_{2.5}\right] \cdot 9 \mathrm{H}_{2} \mathrm{O} /\left[\mathrm{Cd}_{2}(\mathrm{~L} 3)\left(2,6-\mathrm{NDC}_{2}\right] \cdot\right.} \\
\mathrm{DMF} \cdot 5 \mathrm{H}_{2} \mathrm{O} /\left[\mathrm{Cd}_{2}(\mathrm{~L} 3)(\mathrm{BPDC})_{2}\right] \cdot \mathrm{DMF} \cdot 9 \mathrm{H}_{2} \mathrm{O}\end{array}$ & $\mathrm{Fe}^{3+}$ & $\begin{array}{l}\text { Competition absorption of } \\
\text { excitation energy and energy transfer }\end{array}$ & 41 \\
\hline & $\begin{array}{c}{\left[\mathrm{NH}_{2}\left(\mathrm{CH}_{3}\right)_{2}\right]\left(\mathrm{H}_{2} \mathrm{O}\right)\left[\mathrm{Zn}_{3}(\mathrm{BTA})(\mathrm{BTC})_{2}\right]} \\
4 \mathrm{DMAC} \cdot 3 \mathrm{H}_{2} \mathrm{O}\end{array}$ & $\mathrm{Ba}^{2+} / \mathrm{Cu}^{2+}$ & Energy transfer & 42 \\
\hline & {$\left[\mathrm{Cd}_{2}(\mathrm{DTP})_{2}(\mathrm{bibp})_{1.5}\right]_{n}$} & $\mathrm{Cu}^{2+}$ & Charge transfer & 43 \\
\hline & $\left\{\mathrm{Zn}_{2}(\mathrm{O}-\mathrm{BTC})\left(4,4^{\prime}-\mathrm{BPY}\right)_{0.5}\left(\mathrm{H}_{2} \mathrm{O}\right)_{1.5}(\mathrm{DMA})_{0.5}\right\}_{n}$ & $\mathrm{Al}^{3+}$ & Electron transfer & 45 \\
\hline & {$\left[\mathrm{Co}_{2}(\mathrm{dmimpym})(\mathrm{nda})_{2}\right]_{n}$} & $\mathrm{Al}^{3+}$ & $\begin{array}{l}\text { Bonding interactions and } \\
\text { electron transfer }\end{array}$ & 47 \\
\hline & Mg-TPP-DHBDC & $\mathrm{Al}^{3+}$ & Coordination bond interactions & 48 \\
\hline & $\begin{array}{c}{\left[\mathrm{Tb}_{4}\left(\mu_{6}-\mathrm{L} 4\right)_{2}(\mu-\mathrm{HCOO})\left(\mu_{3}-\mathrm{OH}\right)_{3}\left(\mu_{3}-\mathrm{O}\right)(\mathrm{DMF})_{2}\right.} \\
\left.\left(\mathrm{H}_{2} \mathrm{O}\right)_{4}\right]_{n}\end{array}$ & $\mathrm{Ce}^{2+}$ & $\begin{array}{l}\text { Competition absorption of } \\
\text { excitation energy, weak interactions } \\
\text { and energy transfer }\end{array}$ & 49 \\
\hline & UiO-66@butyne & $\mathrm{Hg}^{2+}$ & Molecular interactions & 50 \\
\hline & $\left\{\left[\mathrm{Zn}\left(4,4^{\prime}-\mathrm{AP}\right)(5-\mathrm{AIA})\right](\mathrm{DMF})_{0.5}\right\}_{n}$ & $\mathrm{Hg}^{2+}$ & $\begin{array}{l}\text { Electrostatic interactions and electro- } \\
\text { nic interactions }\end{array}$ & 51 \\
\hline \multirow[t]{9}{*}{ Anions } & $\left\{\left[\mathrm{Zn}_{3}(\mathrm{bpanth})(\mathrm{oba})_{3}\right] \cdot 2 \mathrm{DMF}\right\}_{n}$ & $\mathrm{Cr}_{2} \mathrm{O}_{7}^{2-} / \mathrm{CrO}_{4}^{2-}$ & $\begin{array}{l}\text { Competitive absorption of } \\
\text { excitation energy and energy transfer }\end{array}$ & 54 \\
\hline & $\mathrm{Zr}_{6} \mathrm{O}_{4}(\mathrm{OH})_{7}\left(\mathrm{H}_{2} \mathrm{O}\right)_{3}(\mathrm{BTBA})_{3}$ & $\mathrm{Cr}_{2} \mathrm{O}_{7}^{2-}$ & Charge transfer & 55 \\
\hline & $\left\{[\mathrm{Cu}(\text { pytpy })] \cdot \mathrm{NO}_{3} \cdot \mathrm{H}_{2} \mathrm{O}\right\}_{\infty}$ & $\begin{array}{l}\mathrm{F}^{-}, \mathrm{Cl}^{-}, \mathrm{Br}^{-}, \mathrm{I}^{-}, \mathrm{N}_{3}^{-} \\
\mathrm{SCN}^{-}, \mathrm{CO}_{3}^{2-}\end{array}$ & Ion-exchange & 57 \\
\hline & $\left.\left\{\mathrm{Zn}(\mathrm{L} 5)\left(\mathrm{OH}_{2}\right)_{2}\right\}\left(\mathrm{NO}_{3}\right)_{2} \cdot x \mathrm{G}\right]_{n}$ & $\mathrm{ClO}_{4}^{-}, \mathrm{BF}^{-}, \mathrm{PF}_{6}^{-}, \mathrm{CF}_{3} \mathrm{SO}_{3}^{-}$ & Ion-exchange & 59 \\
\hline & {$\left[\mathrm{Ln}_{2} \mathrm{Zn}(\mathrm{L} 6)_{3}\left(\mathrm{H}_{2} \mathrm{O}\right)_{4}\right] \cdot\left(\mathrm{NO}_{3}\right)_{2} \cdot 12 \mathrm{H}_{2} \mathrm{O}$} & $\mathrm{I}^{-}$ & Ion-exchange and energy transfer & 60 \\
\hline & {$\left[\mathrm{Tb}(\text { Mucicate })_{1.5} \cdot 3\left(\mathrm{H}_{2} \mathrm{O}\right)_{2}\right] \cdot 5 \mathrm{H}_{2} \mathrm{O}$} & $\mathrm{CO}_{3}^{2-}$ & Hydrogen bond interactions & 61 \\
\hline & $\left\{\mathrm{Tb}(\mathrm{BTC}) \cdot\left(\mathrm{CH}_{3} \mathrm{OH}\right)\right\}$ & $\mathrm{F}^{-}$ & Hydrogen bond interactions & 62 \\
\hline & Eu-MOF & $\mathrm{F}^{-}$ & $\begin{array}{l}\text { Covalent interactions and } \\
\text { energy transfer }\end{array}$ & 63 \\
\hline & $\begin{array}{c}\text { Tb@Zn-MOFs, }\left\{\left[\mathrm{Zn}_{4}\left(\mathrm{~L}^{3-}\right)_{2}\left(\mathrm{O}^{2-}\right)\left(\mathrm{H}_{2} \mathrm{O}\right)_{2}\right] .\right. \\
4 \mathrm{EtOH}\}_{n}\end{array}$ & $\mathrm{PO}_{3}^{4-}$ & $\begin{array}{c}\text { Coordination interactions and energy } \\
\text { transfer }\end{array}$ & 64 \\
\hline \multirow[t]{4}{*}{ Explosives } & {$\left[\mathrm{Zn}_{2}(\mathrm{bpdc})_{2}(\mathrm{bpee})\right]$} & DNT, DMNB & $\begin{array}{l}\text { Molecular interactions, bonding } \\
\text { interactions and electron transfer }\end{array}$ & 74 \\
\hline & {$\left[\mathrm{NH}_{2}\left(\mathrm{CH}_{3}\right)_{2}\right]_{2}\left[\mathrm{Cd}_{17}(\mathrm{~L} 8)_{12}\left(\mu_{3}-\mathrm{H}_{2} \mathrm{O}\right)_{4}(\mathrm{DMF})_{2}\left(\mathrm{H}_{2} \mathrm{O}\right)_{2}\right]$} & NB & Electron transfer & 75 \\
\hline & {$\left[\mathrm{H}_{2} \mathrm{~N}\left(\mathrm{CH}_{3}\right)_{2}\right] \cdot \mathrm{Zn}(\mathrm{NDC})(\mathrm{atz}) \cdot \mathrm{H}_{2} \mathrm{O}$} & NB & $\begin{array}{c}\text { Competitive absorption of } \\
\text { excitation energy and electron } \\
\text { transfer }\end{array}$ & 76 \\
\hline & Rh6G@Zn-MOF & TNP & $\begin{array}{l}\text { Intermolecular interactions and } \\
\text { energy transfer }\end{array}$ & 78 \\
\hline \multirow[t]{6}{*}{ VOCs } & $\mathrm{Zn}_{2}(\mathrm{bpdc})_{2}($ bpee $)$ & BQ & Electron transfer & 91 \\
\hline & NUS-1 & VOCs & Molecular interactions & 95 \\
\hline & {$\left[\mathrm{Cd}_{2}(\right.$ tppe $\left.)(\mathrm{bpdc})_{2}\left(\mathrm{H}_{2} \mathrm{O}\right)\right]$} & Mesitylene & Electronic interactions & 96 \\
\hline & Tb-MOF & $p$-Xylene & Electron transfer & 99 \\
\hline & Zr-BTDB-fcu-MOF & Amine & Hydrogen bond interactions & 100 \\
\hline & $\begin{array}{c}\mathrm{Ir}^{3+} / \mathrm{Ru}^{2+} @ \mathrm{Zn}-\mathrm{MOF}\left(\mathrm{Me}_{2} \mathrm{NH}_{2}\right)\left[\mathrm{Zn}_{2}(\mathrm{~L} 10)-\right. \\
\left.\left(\mathrm{H}_{2} \mathrm{O}\right)\right] \cdot 4 \mathrm{DMA}\end{array}$ & Fluorobenzene & $\begin{array}{l}\text { Host-guest interactions } \\
\text { and energy transfer }\end{array}$ & 101 \\
\hline Small molecules & $\mathrm{Cu}_{6} \mathrm{~L}_{1} 1_{6} \cdot 3\left(\mathrm{H}_{2} \mathrm{O}\right)(\mathrm{DMSO})$ & Benzene, toluene & Molecular interactions & 105 \\
\hline
\end{tabular}




\begin{tabular}{|c|c|c|c|c|}
\hline Sensing application & MOF & Analyte & Mechanism & Ref. \\
\hline & $\mathrm{Eu}(\mathrm{BTC})\left(\mathrm{H}_{2} \mathrm{O}\right) \cdot 1.5 \mathrm{H}_{2} \mathrm{O}$ & DMF and acetone & Coordination interactions & 106 \\
\hline & $\mathrm{Yb}(\mathrm{BPT})\left(\mathrm{H}_{2} \mathrm{O}\right)(\mathrm{DMF})_{1.5}\left(\mathrm{H}_{2} \mathrm{O}\right)_{1.25^{-}}$ & Acetone & Coordination interactions & 107 \\
\hline & $\mathrm{Tb}(\mathrm{BTC}) \cdot \mathrm{G}$ & Acetone & Energy transfer & 108 \\
\hline & {$\left[\mathrm{Eu}_{2}\left(\mu_{2}-\mathrm{pzdc}\right)\left(\mu_{4}-\mathrm{pzdc}\right)\left(\mu_{2}-\mathrm{ox}\right)\left(\mathrm{H}_{2} \mathrm{O}\right)_{4}\right] \cdot 8 \mathrm{H}_{2} \mathrm{O}$} & Acetone & $\begin{array}{l}\text { Hydrogen bond interactions } \\
\text { and energy transfer }\end{array}$ & 109 \\
\hline & $\mathrm{Na}\left[\mathrm{Tb}(\mathrm{OBA})_{2}\right]_{3} \cdot 0.4 \mathrm{DMF} \cdot 1.5 \mathrm{H}_{2} \mathrm{O}$ & $\mathrm{H}_{2} \mathrm{O}$ & $\begin{array}{l}\text { Coordination interactions } \\
\text { and energy transfer }\end{array}$ & 110 \\
\hline & {$\left[\mathrm{Cd}_{2}(\mathrm{tib})_{2}(\mathrm{bda})_{2}\right] \cdot(\text { solvent })_{n}$} & Ketones & $\begin{array}{l}\text { Competitive absorption of excitation } \\
\text { energy and energy transfer }\end{array}$ & 111 \\
\hline & {$\left[\mathrm{Eu}_{2} \mathrm{~L} 12\left(\mathrm{H}_{2} \mathrm{O}\right)_{4}\right] \cdot 3 \mathrm{DMF}$} & DMF & Energy transfer & 112 \\
\hline & {$\left[\mathrm{Ln}_{2}(\text { fumarate })_{2}(\right.$ oxalate $\left.)\left(\mathrm{H}_{2} \mathrm{O}\right)_{4}\right] \cdot 4 \mathrm{H}_{2} \mathrm{O}$} & $\mathrm{H}_{2} \mathrm{O}$ & Coordination interactions & 113 \\
\hline & {$[\mathrm{Cu}(\mathrm{L} 13)(\mathrm{I})]_{2 n} \cdot 2 n \mathrm{DMF} \cdot n \mathrm{MeCN}$} & Small molecules & $\begin{array}{l}\text { Hydrogen bond interactions } \\
\text { and molecular interactions }\end{array}$ & 114 \\
\hline Gases & {$\left[\mathrm{Zn}_{4} \mathrm{O}(\mathrm{bpz})_{2}(\mathrm{abdc})\right]$.guest (MAF-X11) } & $\mathrm{O}_{2}$ & Energy transfer & 116 \\
\hline & MIL-100(In) $\supset \mathrm{Tb}^{3+}, \mathrm{CPM}-5 \supset \mathrm{Tb}^{3+}$ & $\mathrm{O}_{2}$ & Energy transfer & 117 \\
\hline & $\mathrm{UiO}-66 @ \mathrm{NH}_{2}$ & NO & $\begin{array}{l}\text { Hydrogen bond interactions and } \\
\text { electron transfer }\end{array}$ & 118 \\
\hline & $\mathrm{Eu}^{3+} / \mathrm{Cu}^{2+} @ \mathrm{UiO}-66-(\mathrm{COOH})_{2}$ & $\mathrm{H}_{2} \mathrm{~S}$ & $\begin{array}{l}\text { Bonding interactions } \\
\text { and energy transfer }\end{array}$ & 119 \\
\hline & Al-MIL-53-NO $\mathrm{NMMs}_{2}$ & $\mathrm{H}_{2} \mathrm{~S}$ & Molecular interactions & 120 \\
\hline \multirow[t]{8}{*}{ Bio-molecules } & LMOF-241 & Aflatoxin B1 & Electron transfer & 123 \\
\hline & FITC@ $[\mathrm{Cd}(\mathrm{L} 14) \cdot \text { solvent }]_{n}$ & 3-Nitropropnic acid & Energy transfer & 124 \\
\hline & $\mathrm{UiO}-66-\mathrm{NH}_{2}$ & ssDNA & $\begin{array}{c}\text { Hydrogen bond interactions and } \\
\text { energy transfer }\end{array}$ & 125 \\
\hline & FeTCPP@MOF composites & DNA & & 126 \\
\hline & MIL-101 $\left(\mathrm{Cr}_{3} \mathrm{~F}\left(\mathrm{H}_{2} \mathrm{O}\right)_{2} \mathrm{O}\left[\left(\mathrm{O}_{2} \mathrm{C}\right) \mathrm{C}_{6} \mathrm{H}_{4}\left(\mathrm{CO}_{2}\right)\right]_{3} \cdot n \mathrm{H}_{2} \mathrm{O}\right)$ & HIV-1 DNA & $\begin{array}{l}\text { Electrostatic interactions and energy } \\
\text { transfer }\end{array}$ & 127 \\
\hline & $\mathrm{Ag}^{+} @ \mathrm{Eu}-\mathrm{MOF}$ & Aspartic acid & Energy transfer & 128 \\
\hline & Eu-MOF & Amino acids & Coordination interactions & 129 \\
\hline & $\mathrm{Eu}_{0.1} \mathrm{~Tb}_{0.9}-\mathrm{BTC}(\mathrm{MLMOF}-3)$ & Coumarin & $\begin{array}{l}\text { Hydrogen bond interactions and } \\
\text { energy transfer }\end{array}$ & 130 \\
\hline
\end{tabular}

tential applications of LMOFs in a wide range of fields, such as medical diagnosis and treatment, and photoelectric devices. We believe a brighter future for functionalized LMOFs can be expected with close collaborations between different subjects.

\section{Received 2 June 2019; accepted 27 August 2019;} published online 17 September 2019

1 Zhang JP, Zhou HL, Zhou DD, et al. Controlling flexibility of metal-organic frameworks. Natl Sci Rev, 2018, 5: 907-919

2 Li JR, Sculley J, Zhou HC. Metal-organic frameworks for separations. Chem Rev, 2012, 112: 869-932

3 Fu D, Xu Y, Zhao M, et al. Enhancement of gas-framework interaction in a metal-organic framework by cavity modification. Sci Bull, 2016, 61: 1255-1259

4 Pan L, Parker B, Huang X, et al. Zn(tbip) $\left(\mathrm{H}_{2}\right.$ tbip= 5-tert-butyl isophthalic acid): A Highly stable guest-free microporous metal organic framework with unique gas separation capability. J Am Chem Soc, 2006, 128: 4180-4181

5 Matsuda R, Kitaura R, Kitagawa S, et al. Highly controlled acetylene accommodation in a metal-organic microporous material. Nature, 2005, 436: 238-241

6 Ma L, Abney C, Lin W. Enantioselective catalysis with homochiral metal-organic frameworks. Chem Soc Rev, 2009, 38: 12481256

7 Zheng Y, Qiao SZ. Metal-organic framework assisted synthesis of single-atom catalysts for energy applications. Natl Sci Rev, 2018, 5: 626-627

8 Shultz AM, Farha OK, Hupp JT, et al. A catalytically active, permanently microporous MOF with metalloporphyrin struts. J Am Chem Soc, 2009, 131: 4204-4205

9 Zhang K, Guo W, Liang Z, et al. Metal-organic framework based nanomaterials for electrocatalytic oxygen redox reaction. Sci China Chem, 2019, 62: 417-429 
10 Yoon M, Srirambalaji R, Kim K. Homochiral metal-organic frameworks for asymmetric heterogeneous catalysis. Chem Rev, 2012, 112: 1196-1231

11 Suh MP, Park HJ, Prasad TK, et al. Hydrogen storage in metalorganic frameworks. Chem Rev, 2012, 112: 782-835

12 Li B, Chen B. A flexible metal-organic framework with double interpenetration for highly selective $\mathrm{CO}_{2}$ capture at room temperature. Sci China Chem, 2016, 59: 965-969

13 Zhang XF, Yang Q, Zhao JP, et al. Three interpenetrated copper (II) coordination polymers based on a V-shaped ligand: Synthesis, structures, sorption and magnetic properties. Sci China Chem, 2011, 54: 1446-1453

14 Férey G, Serre C, Devic T, et al. Why hybrid porous solids capture greenhouse gases? Chem Soc Rev, 2011, 40: 550-562

$15 \mathrm{Bu} \mathrm{XH}$, Tong ML, Chang HC, et al. A neutral 3D copper coordination polymer showing $1 \mathrm{D}$ open channels and the first interpenetrating NbO-type network. Angew Chem Int Ed, 2004, 43: 192-195

16 Horcajada P, Gref R, Baati T, et al. Metal-organic frameworks in biomedicine. Chem Rev, 2012, 112: 1232-1268

17 Della Rocca J, Liu D, Lin W. Nanoscale metal-organic frameworks for biomedical imaging and drug delivery. Acc Chem Res, 2011, 44: 957-968

18 Kreno LE, Leong K, Farha OK, et al. Metal-organic framework materials as chemical sensors. Chem Rev, 2012, 112: 1105-1125

19 Cui Y, Yue Y, Qian G, et al. Luminescent functional metal-organic frameworks. Chem Rev, 2012, 112: 1126-1162

20 Qi XL, Lin RB, Chen Q, et al. A flexible metal azolate framework with drastic luminescence response toward solvent vapors and carbon dioxide. Chem Sci, 2011, 2: 2214-2218

21 An J, Shade CM, Chengelis-Czegan DA, et al. Zinc-adeninate metal-organic framework for aqueous encapsulation and sensitization of near-infrared and visible emitting lanthanide cations. J Am Chem Soc, 2011, 133: 1220-1223

22 Takashima Y, Martínez VM, Furukawa S, et al. Molecular decoding using luminescence from an entangled porous framework. Nat Commun, 2011, 2: 168-176

23 Zhang Y, Yuan S, Day G, et al. Luminescent sensors based on metal-organic frameworks. Coord Chem Rev, 2018, 354: 28-45

24 Wang T, Jia Y, Chen Q, et al. A new luminescent metal-organic framework for selective sensing of nitroaromatic explosives. Sci China Chem, 2016, 59: 959-964

25 Allendorf MD, Bauer CA, Bhakta RK, et al. Luminescent metalorganic frameworks. Chem Soc Rev, 2009, 38: 1330-1352

26 Yaghi OM, O'Keeffe M, Ockwig NW, et al. Reticular synthesis and the design of new materials. Nature, 2003, 423: 705-714

27 Hu Z, Deibert BJ, Li J. Luminescent metal-organic frameworks for chemical sensing and explosive detection. Chem Soc Rev, 2014, 43: 5815-5840

28 Evans JD, Sumby CJ, Doonan CJ. Post-synthetic metalation of metal-organic frameworks. Chem Soc Rev, 2014, 43: 5933-5951

$29 \mathrm{Lu} \mathrm{Z}, \mathrm{Wu} \mathrm{M}, \mathrm{Wu} \mathrm{S}$, et al. Modulating the optical properties of the AIE fluophor confined within UiO-66's nanochannels for chemical sensing. Nanoscale, 2016, 8: 17489-17495

30 Mahata P, Mondal SK, Singha DK, et al. Luminescent rare-earthbased MOFs as optical sensors. Dalton Trans, 2017, 46: 301-328

31 Müller-Buschbaum K, Beuerle F, Feldmann C. MOF based luminescence tuning and chemical/physical sensing. Microporous Mesoporous Mater, 2015, 216: 171-199

32 Banerjee D, Hu Z, Li J. Luminescent metal-organic frameworks as explosive sensors. Dalton Trans, 2014, 43: 10668-10685

33 Liu ZQ, Huang YQ, Sun WY. Progress in fluorescent recognition and sensing of solvent and small organic molecules based on metal-organic frameworks. Chin J Inorg Chem, 2017, 33: 19591969

34 Li J, Wang X, Zhao G, et al. Metal-organic framework-based materials: superior adsorbents for the capture of toxic and radioactive metal ions. Chem Soc Rev, 2018, 47: 2322-2356

35 Bricks JL, Kovalchuk A, Trieflinger C, et al. On the development of sensor molecules that display $\mathrm{Fe}^{\mathrm{III}}$-amplified fluorescence. J Am Chem Soc, 2005, 127: 13522-13529

36 Brugnara C. Iron deficiency and erythropoiesis: new diagnostic approaches. Clin Chem, 2003, 49: 1573-1578

37 Liu ZQ, Chen K, Zhao Y, et al. Structural diversity and sensing properties of metal-organic frameworks with multicarboxylate and $1 H$-imidazol-4-yl-containing ligands. Cryst Growth Des, 2018, 18: 1136-1146

38 Zhao XL, Tian D, Gao Q, et al. A chiral lanthanide metal-organic framework for selective sensing of Fe(III) ions. Dalton Trans, 2016, 45: 1040-1046

39 Wen RM, Han SD, Ren GJ, et al. A flexible zwitterion ligand based lanthanide metal-organic framework for luminescence sensing of metal ions and small molecules. Dalton Trans, 2015, 44: 10914-10917

40 Wang L, Yao ZQ, Ren GJ, et al. A luminescent metal-organic framework for selective sensing of $\mathrm{Fe}^{3+}$ with excellent recyclability. Inorg Chem Commun, 2016, 65: 9-12

41 Zhao D, Liu XH, Zhao Y, et al. Luminescent Cd(II)-organic frameworks with chelating $\mathrm{NH}_{2}$ sites for selective detection of Fe(III) and antibiotics. J Mater Chem A, 2017, 5: 15797-15807

42 Li YW, Li JR, Wang LF, et al. Microporous metal-organic frameworks with open metal sites as sorbents for selective gas adsorption and fluorescence sensors for metal ions. J Mater Chem A, 2013, 1: 495-499

43 Yang L, Lian C, Li X, et al. Highly selective bifunctional luminescent sensor toward nitrobenzene and $\mathrm{Cu}^{2+}$ ion based on $\mathrm{mi}-$ croporous metal-organic frameworks: Synthesis, structures, and properties. ACS Appl Mater Interfaces, 2017, 9: 17208-17217

44 Zhou X, Cheng J, Li L, et al. A europium(III) metal-organic framework as ratiometric turn-on luminescent sensor for $\mathrm{Al}^{3+}$ ions. Sci China Mater, 2018, 61: 752-757

$45 \mathrm{Yu} \mathrm{MH}, \mathrm{Hu}$ TL, Bu XH. A metal-organic framework as a "turn on" fluorescent sensor for aluminum ions. Inorg Chem Front, 2017, 4: 256-260

46 Wang R, Liu X, Huang A, et al. Unprecedented solvent-dependent sensitivities in highly efficient detection of metal ions and nitroaromatic compounds by a fluorescent barium metal-organic framework. Inorg Chem, 2016, 55: 1782-1787

47 Chen WM, Meng XL, Zhuang GL, et al. A superior fluorescent sensor for $\mathrm{Al}^{3+}$ and $\mathrm{UO}_{2}^{2+}$ based on a $\mathrm{Co}(\mathrm{II})$ metal-organic framework with exposed pyrimidyl Lewis base sites. J Mater Chem A, 2017, 5: 13079-13085

48 Li YP, Zhu XH, Li SN, et al. Highly selective and sensitive turnoff-on fluorescent probes for sensing $\mathrm{Al}^{3+}$ ions designed by regulating the excited-state intramolecular proton transfer process in metal-organic frameworks. ACS Appl Mater Interfaces, 2019, 11: 11338-11348

49 Zhang Q, Wang J, Kirillov AM, et al. Multifunctional Ln-MOF luminescent probe for efficient sensing of $\mathrm{Fe}^{3+}, \mathrm{Ce}^{3+}$, and acetone. ACS Appl Mater Interfaces, 2018, 10: 23976-23986 
50 Samanta P, Desai AV, Sharma S, et al. Selective recognition of $\mathrm{Hg}^{2+}$ ion in water by a functionalized metal-organic framework (MOF) based chemodosimeter. Inorg Chem, 2018, 57: 2360-2364

51 Pankajakshan A, Kuznetsov D, Mandal S. Ultrasensitive detection of $\mathrm{Hg}(\mathrm{II})$ ions in aqueous medium using zinc-based metalorganic framework. Inorg Chem, 2019, 58: 1377-1381

52 Mon M, Bruno R, Ferrando-Soria J, et al. Metal-organic framework technologies for water remediation: towards a sustainable ecosystem. J Mater Chem A, 2018, 6: 4912-4947

53 Bolisetty S, Peydayesh M, Mezzenga R. Sustainable technologies for water purification from heavy metals: review and analysis. Chem Soc Rev, 2019, 48: 463-487

54 Yao ZQ, Li GY, Xu J, et al. A water-stable luminescent $\mathrm{Zn}^{\text {II }}$ metalorganic framework as chemosensor for high-efficiency detection of $\mathrm{Cr}^{\mathrm{VI}}$-anions $\left(\mathrm{Cr}_{2} \mathrm{O}_{7}{ }^{2-}\right.$ and $\left.\mathrm{CrO}_{4}{ }^{2-}\right)$ in aqueous solution. Chem Eur J, 2018, 24: 3192-3198

55 He T, Zhang YZ, Kong XJ, et al. Zr(IV)-based metal-organic framework with $\mathrm{T}$-shaped ligand: Unique structure, high stability, selective detection, and rapid adsorption of $\mathrm{Cr}_{2} \mathrm{O}_{7}{ }^{2-}$ in water. ACS Appl Mater Interfaces, 2018, 10: 16650-16659

56 Lustig WP, Mukherjee S, Rudd ND, et al. Metal-organic frameworks: functional luminescent and photonic materials for sensing applications. Chem Soc Rev, 2017, 46: 3242-3285

57 Chen YQ, Li GR, Chang Z, et al. A Cu(I) metal-organic framework with 4 -fold helical channels for sensing anions. Chem Sci, 2013, 4: 3678-3682

58 Ma JP, Yu Y, Dong YB. Fluorene-based Cu(II)-MOF: a visual colorimetric anion sensor and separator based on an anionexchange approach. Chem Commun, 2012, 48: 2946-2948

59 Manna B, Joarder B, Desai AV, et al. Anion-responsive tunable bulk-phase homochirality and luminescence of a cationic framework. Chem Eur J, 2014, 20: 12399-12404

60 Shi PF, Hu HC, Zhang ZY, et al. Heterometal-organic frameworks as highly sensitive and highly selective luminescent probes to detect $\mathrm{I}^{-}$ions in aqueous solutions. Chem Commun, 2015, 51: 3985-3988

61 Wong KL, Law GL, Yang YY, et al. A highly porous luminescent terbium-organic framework for reversible anion sensing. Adv Mater, 2006, 18: 1051-1054

62 Chen B, Wang L, Zapata F, et al. A luminescent microporous metal-organic framework for the recognition and sensing of anions. J Am Chem Soc, 2008, 130: 6718-6719

63 Yang ZR, Wang MM, Wang XS, et al. Boric-acid-functional lanthanide metal-organic frameworks for selective ratiometric fluorescence detection of fluoride ions. Anal Chem, 2017, 89: 1930-1936

64 Ji G, Gao X, Zheng T, et al. Postsynthetic metalation metalorganic framework as a fluorescent probe for the ultrasensitive and reversible detection of $\mathrm{PO}_{4}^{3-}$ ions. Inorg Chem, 2018, 57: 10525-10532

65 Chen Q, Cheng J, Wang J, et al. A fluorescent Eu(III) MOF for highly selective and sensitive sensing of picric acid. Sci China Chem, 2019, 62: 205-211

66 Tian D, Chen RY, Xu J, et al. A three-dimensional metal-organic framework for selective sensing of nitroaromatic compounds. APL Mater, 2014, 2: 124111-124117

67 Sun XC, Wang Y, Lei Y. Fluorescence based explosive detection: From mechanisms to sensory materials. Chem Soc Rev, 2015, 44: 8019-8061 organic framework demonstrating unique selectivity for detection of high explosives and aromatic compounds. J Am Chem Soc, 2011, 133: 4153-4155

69 Buragohain A, Yousufuddin M, Sarma M, et al. 3D luminescent amide-functionalized cadmium tetrazolate framework for selective detection of 2,4,6-trinitrophenol. Cryst Growth Des, 2016, 16: 842-851

70 Zhang L, Kang Z, Xin X, et al. Metal-organic frameworks based luminescent materials for nitroaromatics sensing. CrystEngComm, 2016, 18: 193-206

71 Nagarkar SS, Desai AV, Samanta P, et al. Aqueous phase selective detection of 2,4,6-trinitrophenol using a fluorescent metalorganic framework with a pendant recognition site. Dalton Trans, 2015, 44: 15175-15180

72 Mukherjee S, Desai AV, Manna B, et al. Exploitation of guest accessible aliphatic amine functionality of a metal-organic framework for selective detection of 2,4,6-trinitrophenol (TNP) in water. Cryst Growth Des, 2015, 15: 4627-4634

73 Liu Y, Zhao Y, Liu XH, et al. Novel metal-organic frameworks with high stability for selectively sensing nitroaromatics. Dalton Trans, 2018, 47: 15399-15404

74 Lan $\mathrm{A}, \mathrm{Li} \mathrm{K}, \mathrm{Wu} \mathrm{H}$, et al. A luminescent microporous metalorganic framework for the fast and reversible detection of high explosives. Angew Chem Int Ed, 2009, 48: 2334-2338

75 Tian D, Li Y, Chen RY, et al. A luminescent metal-organic framework demonstrating ideal detection ability for nitroaromatic explosives. J Mater Chem A, 2014, 2: 1465-1470

76 Liu XJ, Wang $\mathrm{X}, \mathrm{Xu}$ JL, et al. Selective gas adsorption and fluorescence sensing response of a $\mathrm{Zn}$ (II) metal-organic framework constructed by a mixed-ligand strategy. Dalton Trans, 2017, 46: 4893-4897

77 Deng Y, Chen N, Li Q, et al. Highly fluorescent metal-organic frameworks based on a benzene-cored tetraphenylethene derivative with the ability to detect 2,4,6-trinitrophenol in water. Cryst Growth Des, 2017, 17: 3170-3177

78 Chen DM, Zhang NN, Liu CS, et al. Dual-emitting dye@MOF composite as a self-calibrating sensor for 2,4,6-trinitrophenol. ACS Appl Mater Interfaces, 2017, 9: 24671-24677

79 Rouhani F, Morsali A, Retailleau P. Simple one-pot preparation of a rapid response AIE fluorescent metal-organic framework. ACS Appl Mater Interfaces, 2018, 10: 36259-36266

80 Slater JM, Watt EJ, Freeman NJ, et al. Gas and vapour detection with poly(pyrrole) gas sensors. Analyst, 1992, 117: 1265-1270

81 Aggazzotti G, Fantuzzi G, Righi E, et al. Blood and breath analyses as biological indicators of exposure to trihalomethanes in indoor swimming pools. Sci Total Environ, 1998, 217: 155-163

82 Mølhave L, Bach B, Pedersen OF. Human reactions to low concentrations of volatile organic compounds. Environ Int, 1986, 12: $167-175$

83 Guo H, Lee SC, Chan LY, et al. Risk assessment of exposure to volatile organic compounds in different indoor environments. Environ Res, 2004, 94: 57-66

84 Wang F, Dong C, Wang Z, et al. Fluorescence detection of anilines and photocatalytic degradation of rhodamine $\mathrm{B}$ by a multifunctional metal-organic framework. Eur J Inorg Chem, 2014, 2014: 6239-6245

85 Wang H, Lustig WP, Li J. Sensing and capture of toxic and hazardous gases and vapors by metal-organic frameworks. Chem Soc Rev, 2018, 47: 4729-4756

86 Xie BP, Qiu GH, Hu PP, et al. Simultaneous detection of Dengue 
and Zika virus RNA sequences with a three-dimensional $\mathrm{Cu}$ based zwitterionic metal-organic framework, comparison of single and synchronous fluorescence analysis. Sensor Actuat BChem, 2018, 254: 1133-1140

87 Leidinger M, Rieger M, Sauerwald T, et al. Integrated pre-concentrator gas sensor microsystem for ppb level benzene detection. Sensor Actuat B-Chem, 2016, 236: 988-996

88 Yan B. Lanthanide-functionalized metal-organic framework hybrid systems to create multiple luminescent centers for chemical sensing. Acc Chem Res, 2017, 50: 2789-2798

89 Marini A, Munoz-Losa A, Biancardi A, et al. What is solvatochromism? J Phys Chem B, 2010, 114: 17128-17135

90 Janzen MC, Ponder JB, Bailey DP, et al. Colorimetric sensor arrays for volatile organic compounds. Anal Chem, 2006, 78: 35913600

91 Lan A, Li K, Wu H, et al. RPM3: A multifunctional microporous MOF with recyclable framework and high $\mathrm{H}_{2}$ binding energy. Inorg Chem, 2009, 48: 7165-7173

92 Liu XG, Wang H, Chen B, et al. A luminescent metal-organic framework constructed using a tetraphenylethene-based ligand for sensing volatile organic compounds. Chem Commun, 2015, 51: $1677-1680$

93 Wang F, Liu W, Teat SJ, et al. Chromophore-immobilized luminescent metal-organic frameworks as potential lighting phosphors and chemical sensors. Chem Commun, 2016, 52: 1024910252

94 Shustova NB, Ong TC, Cozzolino AF, et al. Phenyl ring dynamics in a tetraphenylethylene-bridged metal-organic framework: Implications for the mechanism of aggregation-induced emission. J Am Chem Soc, 2012, 134: 15061-15070

95 Zhang M, Feng G, Song Z, et al. Two-dimensional metal-organic framework with wide channels and responsive turn-on fluorescence for the chemical sensing of volatile organic compounds. J Am Chem Soc, 2014, 136: 7241-7244

96 Zhao X, Li Y, Chang Z, et al. A four-fold interpenetrated metalorganic framework as a fluorescent sensor for volatile organic compounds. Dalton Trans, 2016, 45: 14888-14892

97 Hong Y, Lam JWY, Tang BZ. Aggregation-induced emission. Chem Soc Rev, 2011, 40: 5361

98 Parrott EPJ, Tan NY, Hu R, et al. Direct evidence to support the restriction of intramolecular rotation hypothesis for the mechanism of aggregation-induced emission: temperature resolved terahertz spectra of tetraphenylethene. Mater Horiz, 2014, 1: 251258

99 Chen DM, Zhang NN, Liu CS, et al. Template-directed synthesis of a luminescent Tb-MOF material for highly selective $\mathrm{Fe}^{3+}$ and $\mathrm{Al}^{3+}$ ion detection and VOC vapor sensing. J Mater Chem C, 2017, 5: 2311-2317

100 Mallick A, El-Zohry AM, Shekhah O, et al. Unprecedented ultralow detection limit of amines using a thiadiazole-functionalized $\mathrm{Zr}(\mathrm{IV})$-based metal-organic framework. J Am Chem Soc, 2019, 141: 7245-7249

101 Zhao H, Ni J, Zhang JJ, et al. A trichromatic MOF composite for multidimensional ratiometric luminescent sensing. Chem Sci, 2018, 9: 2918-2926

102 Zhao D, Cui Y, Yang Y, et al. Sensing-functional luminescent metal-organic frameworks. CrystEngComm, 2016, 18: 3746-3759

103 Jia YY, Zhang YH, Xu J, et al. A high-performance "sweeper" for toxic cationic herbicides: an anionic metal-organic framework with a tetrapodal cage. Chem Commun, 2015, 51: 17439-17442
104 Liu ZQ, Zhao Y, Deng Y, et al. Selectively sensing and adsorption properties of nickel(II) and cadmium(II) architectures with rigid $1 H$-imidazol-4-yl containing ligands and 1,3,5-tri(4-carboxyphenyl)benzene. Sensor Actuat B-Chem, 2017, 250: 179-188

105 Bai Y, He G, Zhao Y, et al. Porous material for absorption and luminescent detection of aromatic molecules in water. Chem Commun, 2006, 43: 1530

106 Chen B, Yang Y, Zapata F, et al. Luminescent open metal sites within a metal-organic framework for sensing small molecules. Adv Mater, 2007, 19: 1693-1696

107 Guo Z, Xu H, Su S, et al. A robust near infrared luminescent ytterbium metal-organic framework for sensing of small molecules. Chem Commun, 2011, 47: 5551-5553

108 Xiao Y, Wang L, Cui Y, et al. Molecular sensing with lanthanide luminescence in a $3 \mathrm{D}$ porous metal-organic framework. J Alloys Compd, 2009, 484: 601-604

109 Ma D, Wang W, Li Y, et al. In situ 2,5-pyrazinedicarboxylate and oxalate ligands synthesis leading to a microporous europiumorganic framework capable of selective sensing of small molecules. CrystEngComm, 2010, 12: 4372-4377

110 Lin YW, Jian BR, Hsu KF, et al. Synthesis and characterization of three ytterbium coordination polymers featuring various cationic species and a luminescence study of a terbium analogue with open channels. Inorg Chem, 2010, 49: 2316-2324

111 Liu XJ, Zhang YH, Chang Z, et al. A water-stable metal-organic framework with a double-helical structure for fluorescent sensing. Inorg Chem, 2016, 55: 7326-7328

112 Li Y, Zhang S, Song D. A luminescent metal-organic framework as a turn-on sensor for DMF vapor. Angew Chem Int Ed, 2013, 52: $710-713$

113 Zhu WH, Wang ZM, Gao S. Two 3D porous lanthanidefumarate-oxalate frameworks exhibiting framework dynamics and luminescent change upon reversible de- and rehydration. Inorg Chem, 2007, 46: 1337-1342

114 Khatua S, Goswami S, Biswas S, et al. Stable multiresponsive luminescent MOF for colorimetric detection of small molecules in selective and reversible manner. Chem Mater, 2015, 27: 53495360

115 Wu S, Min H, Shi W, et al. Multicenter metal-organic frameworkbased ratiometric fluorescent sensors. Adv Mater, 2019, 341: 1805871

116 Lin RB, Li F, Liu SY, et al. A noble-metal-free porous coordination framework with exceptional sensing efficiency for oxygen. Angew Chem Int Ed, 2013, 52: 13429-13433

117 Dou Z, Yu J, Cui Y, et al. Luminescent metal-organic framework films as highly sensitive and fast-response oxygen sensors. J Am Chem Soc, 2014, 136: 5527-5530

118 Desai AV, Samanta P, Manna B, et al. Aqueous phase nitric oxide detection by an amine-decorated metal-organic framework. Chem Commun, 2015, 51: 6111-6114

119 Zhang X, Hu Q, Xia T, et al. Turn-on and ratiometric luminescent sensing of hydrogen sulfide based on metal-organic frameworks. ACS Appl Mater Interfaces, 2016, 8: 32259-32265

120 Zhang X, Zhang Q, Yue D, et al. Flexible metal-organic framework-based mixed-matrix membranes: A new platform for $\mathrm{H}_{2} \mathrm{~S}$ sensors. Small, 2018, 14: 1801563

121 Chernikova V, Yassine O, Shekhah O, et al. Highly sensitive and selective $\mathrm{SO}_{2}$ MOF sensor: the integration of MFM-300 MOF as a sensitive layer on a capacitive interdigitated electrode. J Mater Chem A, 2018, 6: 5550-5554 
Zhang Q, Wang CF, Lv YK. Luminescent switch sensors for the detection of biomolecules based on metal-organic frameworks. Analyst, 2018, 143: 4221-4229

123 Hu Z, Lustig WP, Zhang J, et al. Effective detection of mycotoxins by a highly luminescent metal-organic framework. J Am Chem Soc, 2015, 137: 16209-16215

124 Tian D, Liu XJ, Feng R, et al. Microporous luminescent metalorganic framework for a sensitive and selective fluorescence sensing of toxic mycotoxin in moldy sugarcane. ACS Appl Mater Interfaces, 2018, 10: 5618-5625

125 Zhang HT, Zhang JW, Huang G, et al. An amine-functionalized metal-organic framework as a sensing platform for DNA detection. Chem Commun, 2014, 50: 12069-12072

126 Ling P, Lei J, Zhang L, et al. Porphyrin-encapsulated metalorganic frameworks as mimetic catalysts for electrochemical DNA sensing via allosteric switch of hairpin DNA. Anal Chem, 2015, 87: 3957-3963

127 Fang JM, Leng F, Zhao XJ, et al. Metal-organic framework MIL101 as a low background signal platform for label-free DNA detection. Analyst, 2014, 139: 801-806

128 Weng H, Yan B. A sliver ion fabricated lanthanide complex as a luminescent sensor for aspartic acid. Sensor Actuat B-Chem, 2017, 253: 1006-1011

129 Zhao Y, Wan MY, Bai JP, et al. pH-Modulated luminescence switching in a Eu-MOF: rapid detection of acidic amino acids. J Mater Chem A, 2019, 7: 11127-11133

130 Gao Y, Yu G, Liu K, et al. Luminescent mixed-crystal Ln-MOF thin film for the recognition and detection of pharmaceuticals. Sensor Actuat B-Chem, 2018, 257: 931-935

Acknowledgements This work was financially supported by the National Natural Science Foundation of China (21531005, 21421001, 21905142, and 91856124), and the Programme of Introducing Talents of Discipline to Universities (B18030).

Author contributions He J prepared the manuscript under the guidance of $\mathrm{Li} \mathrm{N}, \mathrm{Bu} \mathrm{XH}$. Yin J searched the references. Xu J, Li N, and Bu $\mathrm{XH}$ revised the manuscript. All authors contributed to the general discussion and revision of the manuscript.

Conflict of interest The authors declare that they have no conflict of interest.

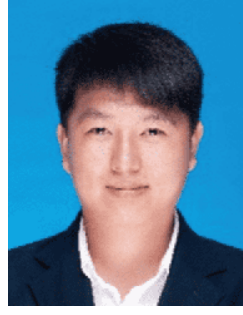

Jie He received his BSc degree in chemistry in 2015 from Hexi University and MSc degree at Hubei University in 2018. Now, he is pursuing his $\mathrm{PhD}$ degree at the School of Materials Science and Engineering, Nankai University under the supervision of Prof. Xian-He Bu. His research interests focus on the controlled synthesis of MOFs and their applications in luminescent sensing and catalysis.

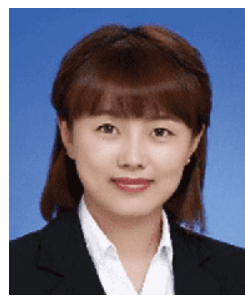

Na Li obtained her $\mathrm{PhD}$ degree in inorganic chemistry in 2018 from Nankai University under the supervision of Prof. Xian-He Bu. Then, she joined Prof. Bu's group as a postdoctoral research associate at Nankai University. Her recent research focuses on the design, controlled synthesis, and applications of new porous materials.

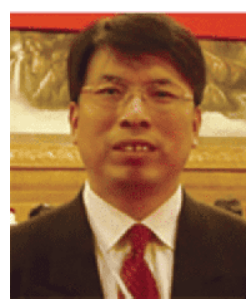

Xian-He Bu received his $\mathrm{BSc}$ and $\mathrm{PhD}$ degrees from Nankai University in 1986 and 1992 under the supervision of Prof. Yun-Ti Chen. He was promoted to a full professor in 1995. He was a visiting professor at Tokyo University (1999), Kyoto University (2002), IMS (1998), CUHK (2002) and HKUST (2004). In 2002, he won the support of the National Outstanding Youth Foundation; in 2004, he was selected as Cheung Kong Scholar Professor by the Ministry of Education. He is now the dean of School of Materials Science and Engineering of Nankai University. His research focuses on functional coordination chemistry, MOFs, crystal engineering, molecular magnetism, etc.

\section{基于苂光金属有机框架的化学检测器研究进展}

何杰 ${ }^{1}$, 徐加良 ${ }^{1}$, 尹佳成 ${ }^{1}$, 李娜 ${ }^{1 *}$, 卜显和 ${ }^{1,2 *}$

摘要 由金属离子/簇与有机配体构筑的金属有机框架(metal-organic frameworks, MOFs)近年来受到广泛关注. 作为一类典型的MOFs材料, 苂光MOFs(LMOFs) 因具有结晶度高、结构多样、孔隙率可调、孔道 易修饰等特点在化学检测领域展现出重要的应用前景. 迄今为止, 大 量的LMOFs 已被合成并用于多种物质检测. 本文综述了LMOFs对金 属阳离子、阴离子、小分子、有机物、爆炸物、气体、生物分子等 物质检测的近期研究进展, 总结了苂光检测机理和结构-性能关系, 为 后续定向构筑性能优异的新型LMOFs 材料提供参考. 